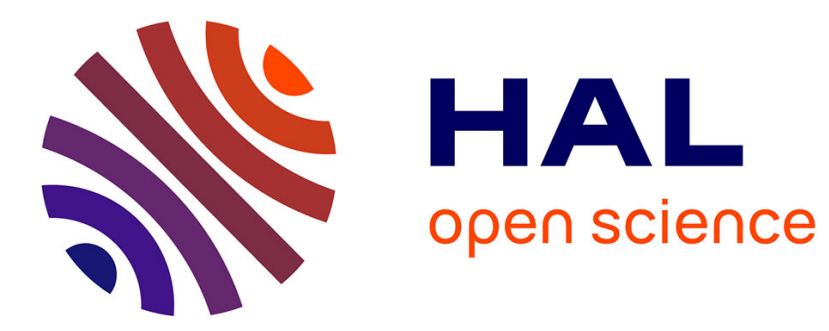

\title{
Sources des inscriptions médiévales
}

Robert Favreau

\section{To cite this version:}

Robert Favreau. Sources des inscriptions médiévales. Comptes-rendus des séances de l'Académie des inscriptions et belles-lettres, 2009, 153 (4), pp.1277-1330. 10.3406/crai.2009.92703 . halshs-03199230

\section{HAL Id: halshs-03199230 \\ https://shs.hal.science/halshs-03199230}

Submitted on 15 Apr 2021

HAL is a multi-disciplinary open access archive for the deposit and dissemination of scientific research documents, whether they are published or not. The documents may come from teaching and research institutions in France or abroad, or from public or private research centers.
L'archive ouverte pluridisciplinaire HAL, est destinée au dépôt et à la diffusion de documents scientifiques de niveau recherche, publiés ou non, émanant des établissements d'enseignement et de recherche français ou étrangers, des laboratoires publics ou privés. 


\section{Sources des inscriptions médiévales}

Robert Favreau

\section{Citer ce document / Cite this document :}

Favreau Robert. Sources des inscriptions médiévales. In: Comptes rendus des séances de l'Académie des Inscriptions et Belles-Lettres, 153e année, N. 4, 2009. pp. 1277-1330;

doi : https://doi.org/10.3406/crai.2009.92703

https://www.persee.fr/doc/crai_0065-0536_2009_num_153_4_92703

Fichier pdf généré le 19/07/2018 


\title{
COMMUNICATION
}

\author{
SOURCES DES INSCRIPTIONS MÉDIÉVALES, \\ PAR M. ROBERT FAVREAU, CORRESPONDANT DE L'ACADÉMIE
}

Tout épigraphiste est amené à se poser la question des sources auxquelles ont puisé les auteurs d'inscriptions. Plus son champ de recherche s'élargit, plus apparaissent des convergences, et plus, en même temps, il se rend compte que cette quête ne sera jamais terminée, car chaque auteur a son histoire personnelle, sa culture, des sources différentes à sa disposition. À défaut de pouvoir donner une synthèse pleinement satisfaisante, il apparaît utile de faire le point à un moment donné - en l'espèce la réalisation d'un fichier général de sources, expressions, formules - comme une étape d'un travail qui sera sans cesse à remettre sur le métier.

\section{L’Antiquité}

Un premier champ à explorer est celui des auteurs de l'Antiquité classique, qu'un emprunt soit direct ou à partir de citations faites par quelque auteur chrétien. Virgile est à retenir en premier, car on en a fait parfois un auteur pré-chrétien, avec par exemple ce vers de la quatrième Églogue :

JAM NOVA PROGENIES CAELO DE MITTITUR ALTO ${ }^{1}$

« Déjà une nouvelle progéniture est envoyée du haut du ciel ».

Ce vers figure au portail gauche de la façade occidentale de la cathédrale de Laon au XII ${ }^{\mathrm{e}}$ siècle ${ }^{2}$, et est aussi inscrit dans les peintures murales romanes récemment découvertes des Salles-Lavauguyon en Limousin ${ }^{3}$. On le retrouvera dans les stalles de la cathédrale d'Ulm au XV $\mathrm{XV}^{\mathrm{e}} \mathrm{s}$. Il y a sans doute une réminiscence virgilienne dans

1. Bucoliques, quatrième Églogue, vers 7 ; J. Carcopino, Virgile et le mystère de la IVe Églogue, Paris, 1930 ; P. Courcelle, « Les exégèses chrétiennes de la quatrième Églogue », Revue des études anciennes 59, 1957, p. 294-319.

2. É. Male, L'art religieux du XIII siècle en France, Paris, 1931, p. 148-149, 152.

3. M.-Th. Camus, "Programme iconographique des peintures de Saint-Eutrope de SallesLavauguyon », Cahiers de civilisation médiévale 33, 1990, p. 143. 
le nova progenies d'une inscription de Saint-Jean-de-Latran vers $1300^{4}$. Raphaël reprendra le vers à Sainte-Marie-de-la-Paix à Rome en 1514. Peut-être ce vers a-t-il été pris dans le Sermon contre les ariens, les juifs et les païens de l'évêque de Carthage Quodvultdeus, qu'on attribuait alors à saint Augustin, où il figure comme une citation du poeta facundissimus. Il est aussi dans une hymne médiévale $^{5}$. La référence aux Bucoliques de Virgile est claire, et un peu étonnante, dans l'inscription du bâton pastoral de l'archevêque de Cologne Anno (1056-1075) à Saint-Servais de Siegburg :

TITYRE COGE PECUS CECOS NE DUCITO CECUS

«Tityre, rassemble le troupeau, ne conduis pas en aveugle des aveugles $»^{6}$.

Le pape Damase a inséré dans un de ses épigrammes un vers de l'Énéide, et on a repéré d'autres emprunts à l'Énéide dans des inscriptions de l'Afrique chrétienne ${ }^{7}$. Les vertus cardinales sont héritées de Socrate, par l'intermédiaire de Platon et du De officiis de Cicéron. Aussi y a-t-il une certaine logique à avoir employé, dans les fonts baptismaux de la cathédrale d'Hildesheim au deuxième quart du XIII ${ }^{\mathrm{e}}$ siècle, un vers de l'Art poétique d'Horace pour commenter la Tempérance :

OMNE TULIT PUNCTUM QUI MISCUIT UTILE DULCI

«Il a obtenu tous les suffrages celui qui a mélangé l'utile à l'agréable »,

et, pour illustrer, la Justice, une citation de la Sagesse 11, 21 inspirée de Sophocle, Gorgias, Platon et de la jurisprudence romaine comme l'a montré Henri de Lubac ${ }^{8}$. Le portrait de Caton par Lucain dans la Pharsale:

JUSTITIAE CULTOR, RIGIDI SERVATOR HONESTI IN COMMUNE BONUS NULLOSQUE CATONIS IN ACTUS ${ }^{9}$

4. V. Forcella, Iscrizioni delle chiese e d'altri edifici di Roma dal secolo XI ai giorni nostri, Rome, VIII, 1876, p. 16, $\mathrm{n}^{\circ} 18$ : qui nova progenies ipso favente subacti.

5. Analecta hymnica Medii Aevi, L, Hymnographi latini. Lateinische Hymnedichter, Leipzig, 1907, p. 554

6. Bucoliques, III, 20 : Ornamenta ecclesiae. Kunst und Künstler der Romanik, 1, Cologne, 1985, p. 452, C 29.

7. R. Favreau, «La mémoire du passé dans les inscriptions du Haut Moyen Âge », dans Ideologie e pratiche del reimpiego nell'alto medioevo, Settimane di studio del Centro italiano di studi sull'alto medioevo, XLVI, Spolète, 1999, p. 964.

8. R. Favreau, « Les inscriptions des fonts baptismaux d'Hildesheim, baptême et quaternité », Cahiers de civilisation médiévale 38, 1995, p. 120-121 : OMNIA IN NUMERO, MENSURA ET PONDERE PONO.

9. Lucain, La guerre civile (La Pharsale), A. Bourgery (éd.), 3e éd. Paris, 1958, t. 1, p. 48 (vers 388-389). 
a inspiré les auteurs médiévaux d'inscriptions. Le premier vers est copié tel quel dans l'épitaphe du cardinal Pietro Capocci à SainteMarie-Majeure à Rome en $1259^{10}$, où l'on trouve un autre emprunt à Lucain. On rencontre le justitiae cultor dans les inscriptions chrétiennes ${ }^{11}$, en Suisse dans l'épitaphe de l'évêque Marius d'Avenche au $\mathrm{VI}^{\mathrm{e}}$ siècle, à Poitiers, dans un vers d'Alcuin, vers 800 , à Saint-Riquier avant 1075, à Avignon aux $\mathrm{XI}^{\mathrm{e}}$-XII ${ }^{\mathrm{e}}$ siècle, dans le rouleau des morts de l'abbesse Mathilde en 1113 à Hautvillers, à Bethléem dans l'épitaphe du roi Amauri en 1175, à Beauvais en 1267, à Viterbe en 1270, à Rouen en 1280, à Saint-Denis au XIII ${ }^{\mathrm{e}}$ siècle, le rigidi servator honesti à Saint-Remi de Reims en 1021, servator honesti à SaintPaul de Rome en 525. Au cimetière de Callixte à Rome, le justitiae cultor vitae servator honestae s'inspire évidemment de Lucain, est repris dans le sylloge de Tours où Alcuin l'a sans doute trouvé, en l'utilisant dans son poème sur York (vers 134). In commune bonus est en 625 à Rome dans l'épitaphe du pape Boniface V, en 1061 à Saint-Pierre de Vienne en Dauphiné, en 1105 à Saint Nicolas de Bari. Les moines de Saint-Benoît-sur-Loire pouvaient méditer sur treize fables de Phèdre, reproduites au début $\mathrm{du} \mathrm{XI}^{\mathrm{e}}$ siècle, en leur réfectoire ${ }^{12}$, et dans la " salle peinte »du premier étage du Vieil évêché de Lausanne, treize sentences des Disticha Catonis étaient peintes sur des banderoles en haut des murs ${ }^{13}$.

De nombreuses expressions d'auteurs de l'Antiquité sont passées chez les auteurs chrétiens du Moyen Âge et se retrouvent dans les inscriptions, sans qu'on puisse être assuré d'un emploi direct ou indirect. Le ONOR HONUS d'une crosse du XI ${ }^{\mathrm{e}}$ siècle à la cathédrale de Saint-Lizier (Ariège) est sans doute un emprunt à Ovide (Épître 9, 31) : non honor est, sed onus, de même que le EST ONUS OMNIS HONOR du tympan dit «Mystère d'Apollon », du XII siècle, au musée Curtius de Liège. Le praemia digna ferant ou feras de Virgile ou d'Ovide ${ }^{14}$ a été repris dans une inscription latine antique ${ }^{15}$,

10. V. Forcella, op. cit. (n. 4), XI, 10, n 4

11. E. Diehl, Inscriptiones latinae christianae veteres, I, Berlin, 1925, p. 36, $\mathrm{n}^{\circ} 135$; p. 195 , $\mathrm{n}^{\circ} 1023$; p. $202, \mathrm{n}^{\circ} 1051$; p. $232, \mathrm{n}^{\circ} 1195$; p. $348, \mathrm{n}^{\circ} 1783$

12. L. Hermann, «Autour des fables de Phèdre », Latomus VII, 1948, p. 203-207 : les fables du réfectoire de Saint-Benoît-sur-Loire.

13. $\mathrm{D}^{\mathrm{r}} \mathrm{E}$. Bach, « Le Vieil-Evêché », dans Congrès archéologique de France. CX $X^{e}$ session tenue en Suisse romande en 1952, Paris, 1953, p. 45-46 ; A. Piaget, « Les inscriptions latines de l'Évêché », Revue historique vaudoise, 1930, p. 174-177.

14. O. Schumann, Lateinisches Hexameter-Lexikon. Dichterisches Formelgut von Ennius bis zum Archipoeta, 4, Munich, 1981 (Monumenta Germaniae Historica, Hilfsmittel, 4, 4), p. $322-323$.

15. Carmina latina epigraphica, Fr. Buechler (éd.), II, Leipzig, 1897, p. 477, $\mathrm{n}^{\circ} 1037$. 
et se trouve aussi dans l'épitaphe de l'abbé Cuno en l'abbatiale de Wissembourg (Bas-Rhin) en 1248 ${ }^{16}$, outre plusieurs emplois de praemia digna dans des inscriptions chrétienne ou médiévales ${ }^{17}$. Le da veniam qu'Ovide emploie treize fois se trouve dans l'épitaphe de Duhoda à Uzès, dans les compositions de Micon de SaintRiquier, à Reims, Tours, Orthez en France, Trèves, Hildesheim, Vornbach, Maulbronn en Allemagne, Rome, Bénévent, Farfa, Milan en Italie. L'omnibus omnis erat de l'épitaphe de Thibaut, comte de Champagne à la cathédrale de Troyes en 1152, par Simon Chèvre d'Or ${ }^{18}$ est probablement emprunté à l'Ars amatoria d'Ovide, et sera repris par le Floridus Aspectus de Pierre Riga ${ }^{19}$. On pourrait multiplier les exemples, mais c'est un domaine où l'épigraphiste trouvera grand profit à collaborer avec un spécialiste de la littérature latine.

Les Oracles sibyllins fournissent un autre exemple de réemploi d'une œuvre de l'Antiquité sous une forme chrétienne. Le Judicii signum tellus sudore madescet, " Signe du jugement la terre s'imprègne de sueur » est prononcé par la sibylle qui annonce l'agonie du Christ au jardin des Oliviers. On a Judicii signum à la cathédrale de Sessa Aurunca en Italie du Sud au XIII ${ }^{\mathrm{e}}$ siècle $^{20}$. Le vers qui suit, e caelo rex adveniet per secla futurus, est en l'église de la Nativité à Bethléem, au portail nord de la façade de la cathédrale de Laon, et dans les peintures murales des Salles-Lavauguyon. Ce sont les deux premiers vers d'un ensemble de vingt-sept vers, que saint Augustin donne dans la Cité de Dieu (1. XVIII, ch. 23) et que son contemporain Quodvultdeus, évêque de Carthage cite dans son Sermon contre les juifs. Les deuxième, troisième, quatrième et vingt-sixième de ces vingt-sept vers sont inscrits au pignon de la châsse de San Millán de la Cogolla.

Les auteurs de l'Antiquité ont été copiés et recopiés. Ainsi de ces vers d'Ovide sur la fragilité de l'homme :

Omnia sunt hominum tenui pendentia filo

Et subito casu quae valuere ruunt ${ }^{21}$.

16. R. Will, « Répertoire des inscriptions romanes de l'Alsace », Revue d'Alsace 98, 1959, p. 83.

17. A. Bordj-Sidi-Messaoui dans l'Afrique chrétienne, à Oviedo, Trobe Deva en Espagne aux $\mathrm{IX}^{\mathrm{e}}$ et $\mathrm{X}^{\mathrm{e}}$ siècles.

18. Histoire littéraire de la France, XII, p. 490.

19. A. Boutemy, «Recherches sur le Floridus aspectus », Latomus, 1949, p. 297.

20. É. Bertaux, L'art dans l'Italie méridionale de la fin de l'empire romain à la conquête de Charles d'Anjou, II, Paris et Rome, 1968, p. 602-603.

21. Ovide, Epistulae ex Ponto, 4, 3, 35-36. 
« Tout ce qui est des hommes est suspendu à un fil fragile

et par une chute soudaine ce qui était plein de force s'écroule. »

Ces deux vers figurent au début de l'épitaphe du cardinal Louis d'Alleman, archevêque d'Arles, à Saint-Trophime en $1450^{22}$. Ils ont pu être copiés directement dans les œuvres d'Ovide, mais aussi dans un florilège $e^{23}$ et ces vers et les deux suivants se trouvent dans les œuvres de saint Anselme ${ }^{24}$, dans celles d'Hildebert de Lavardin ${ }^{25}$, et les deux premiers vers sont cités par Pierre de Blois dans l'une de ses épîtres ${ }^{26}$. Ce problème des copies multiples se pose aussi avec les œuvres des auteurs chrétiens.

\section{Les auteurs chrétiens}

Dans la longue suite des auteurs chrétiens il ne faut pas négliger les petits auteurs des $\mathrm{IV}^{\mathrm{e}}-\mathrm{VI}^{\mathrm{e}}$ siècles, que l'on connaît bien au Moyen Âge. Le poète bordelais Ausone, peut-être un des maîtres d'Hilaire de Poitiers, donne sous forme interrogative des sentences de sages ; Qui est riche ? Quelle est la femme chaste ? Quelle est l'œuvre du prudent ? etc., et de cet ensemble de sept vers ${ }^{27}$, trois sont repris par le Livre des proverbes de Bède et par le Livre des proverbes d'Othlon, moine de Saint-Emmeran ${ }^{28}$, les sept vers sont donnés par Hildebert de Lavardin sous le titre De multiplici veritate, quatre se lisent chez Philippe de Harvengt ${ }^{29}$, et ils sont inscrits sur un tapis de St. Ludgeri (1174-1183) au Braunschweigisches Landesmuseum $^{30}$. Plusieurs des vers d'Ausone sur les signes des mois ${ }^{31}$ sont inscrits dans le pavement de mosaïque de San Savino de Piacenza. $\mathrm{Au} \mathrm{IV} \mathrm{V}^{\mathrm{e}}$ siècle aussi le poète espagnol Juvencus traduit les évangiles en vers, et les huit vers qu'il compose pour les évangélistes sont

22. Gallia christiana, I, C 583 .

23. B. Munk Olsen, "Les classiques latins dans les florilèges médiévaux antérieurs au XIII $\mathrm{e}^{\mathrm{e}}$ siècle », Revue d'histoire des textes IX, 1979, p. 47-121, et X, 1980, p. 115-164. Ce texte d'Ovide y est cité.

24. Patrologie latine, t. 158 , c. 707

25. Ibid., t. 171 , c. $1424, \mathrm{n}^{\circ} 78$

26. Ibid., t. 207, c. 224, epistola 72.

27. Ausone, Septem sapitentium sententiae septenis versibus explicatae, M.G.H., Auctores antiquissimi, 5/2 C. Shenkl (éd.), Berlin, 1883, p. 246-247.

28. Patrologie latine, t. 90 , c. 1108 , et t. 146 , c. 3328

29. Ibid., t. 171, c. 1410 et 1438 ; Patrologie latine, t. 203, c. 1395.

30. Die Inschriften der Stadt Helmsted bis 1060, I. Henze (éd.), Wiesbaden, 2005 (Die Deutschen Inschriften, 61), p. 66, n 2, fig. 5-8.

31. Patrologie latine, t. 119 , c. 912. 
recopiés par les copistes et enlumineurs d'évangéliaires du $\mathrm{VIII}^{\mathrm{e}}$ au $\mathrm{X}^{\mathrm{e}}$ siècle en Irlande, France, Italie, Allemagne. La Psychomachie de Prudence a inspiré les sculpteurs qui ont mis en scène la lutte des vertus et des vices que l'on trouve, avec inscriptions, à ArgentonChâteau ou à Aulnay. Ce sont aussi les évangiles qui sont à la base des 1753 vers du Carmen Paschale de Cœlius Sedulius au V viècle. Les quatre vers, où il rapproche les évangélistes et leur symbole seront à maintes reprises utilisés par les enlumineurs d'évangéliaires qui représentent les évangélistes en tête de chacun de leurs livres et ce dès la fin du VI ${ }^{\mathrm{e}}$ siècle. Ils ont aussi été employés dans les inscriptions : plaque ornementale au Museo cristiano de Cividale en Frioul à la fin du VIII ${ }^{\mathrm{e}}$ siècle, ivoire carolingien de la région de Trèves-Aix au Metropolitan Museum, ivoire carolingien du Musée des Beaux-Arts à Lyon, reliure de l'évangéliaire de Morienval du $\mathrm{X}^{\mathrm{e}}$ siècle à Noyon, vase d'ivoire de l'archevêque Geoffroy au trésor de la cathédrale de Milan fin $X^{\mathrm{e}}$ siècle, table d'autel de Montolieu (Aude) au $\mathrm{X}^{\mathrm{e}}$ siècle, peintures murales romanes de Saint-Plancard (Haute-Garonne), de Saint-Martin-de-Fenollar (Pyrénées-Orientales), de Santa Maria de Mur (aujourd'hui au Museum of Fine Arts de Boston), collatéral sud de la cathédrale d'Aix au XII ${ }^{\mathrm{e}}$ siècle, applique d'une châsse limousine du XIII ${ }^{\mathrm{e}}$ siècle, et un autre vers de Sedulius a inspiré l'inscription du tympan de Tasque (Gers) ${ }^{32}$. La mise en vers des Actes des apôtres par le sous-diacre Arator au $\mathrm{VI}^{\mathrm{e}}$ siècle fait également partie des œuvres mineures qui furent très goûtées au Moyen Âge. C'est dans cet ouvrage que l'on trouve pour la première fois l'expression sine felle columba qui figure dans une douzaine d'inscriptions de France, Belgique, Espagne, Allemagne ${ }^{33}$.

Mais parmi les auteurs des premiers siècles chrétiens il y a des noms incontournables, et d'abord saint Augustin, qui est une continuelle référence pendant le Moyen Âge. Augustin a fait de 1'apparition de trois hommes à Abraham au chêne de Mambré un symbole de la Trinité, car Abraham a vu les trois hommes et il se prosterne devant eux en disant : "Seigneur... " (Genèse 18, 1-3) : Abraham tres vidit et unum adoravit ${ }^{34}$. En l'abbatiale San Marcello de Capoue, dans les années 1070, dans le milieu de l'abbé Didier, on a inscrit :

32. R. Favreau, «Épigraphie et miniatures. Les vers de Sedulius et les évangélistes », Journal des savants, 1993, p. 63-87.

33. R. Favreau, "Sine felle columba. Sources et formation d'une formule épigraphique ", Cahiers de civilisation médiévale 32, 1989, p. 105-113.

34. Contra Maximinum Arianorum episcopum : Quid sibi ergo vult ista visibilis Trinitas et intelligibilis unitas nisi ut nobis insinuaretur quod ita tres essent Pater et Filius et Spiirtus sanctus, 


\section{ANTE FORES RESIDENS TRES VIDIT ADORAT ET UNUM ${ }^{35}$.}

Le texte même d'Augustin se trouve dans l'ambon/retable de Klosterneubourg en 1181 , et sur la porte de bronze de la cathédrale de Monreale à une date voisine ${ }^{36}$, tandis que dans une mosaïque de la nef de la même cathédrale on peut lire : ABRAHAM ANGELOS HOSPITIO SUSCEPIT ET CUM TRES VIESIT UNUM/ADORABIS ( $\mathrm{sic})^{37}$. Dieu, écrit encore Augustin, est le commencement sans avoir luimême de commencement, principium sine principio ${ }^{38}$. C'est sans doute lui qui inspire les inscriptions de Sainte-Thècle de Milan, avant $700^{39}$, de La Lande-de-Fronsac ${ }^{40}$, de la cathédrale de Sens ${ }^{41}$, et d'une plaque émaillée du Louvre ${ }^{42}$ au XII ${ }^{\mathrm{e}}$ siècle, plutôt que Phœbade, évêque d'Agen, qui emploie, avant Augustin, la même expression dans son Liber contra arianos ${ }^{43}$.

Il ne saurait être question de passer en revue tous les auteurs chrétiens qui ont composé des inscriptions ou été copiés pour la composition d'inscriptions. Ce pourrait être l'objet de plusieurs thèses. Quatre auteurs doivent être distingués parmi tous les autres : Venance Fortunat, Eugène de Tolède, Alcuin, Hildebert de Lavardin.

Formé à Ravenne Venance Fortunat avait une connaissance remarquable des œuvres de l'Antiquité, et par là fut toujours prisé des auteurs pour qui l'Antiquité était un modèle lors des « Renaissances " de l'époque carolingienne ou du XII ${ }^{e}$ siècle. Pour une étude sur «Fortunat et l'épigraphie ${ }^{44}$ j'ai repéré environ quatrevingts emprunts à Fortunat dans des inscriptions de France, Italie, Allemagne, Angleterre. Je me contenterai donc de quelques

ut tamen simul non tres dii et domini essent sed unus Dominus Deus?... Abraham tres vidit et unum adoravit (Patrologie latine, t. 42, c. 809).

35. D. F. Glass, Romanesque Sculpture in Campania ..., 1991, p. 63.

36. A. Boekler, Die Bronzetüren des Bonanus von Pisa und des Barisanus von Trani, Berlin, 1953, p. $18-44$

37. O. Demus, The Mosaics of Norman Sicily, Londres, 1950, p. 169

38. De Genesi ad litteram imperfectus liber, c. 3, Patrologie latine, t. 34, c. 222.

39. E. Le Blant, Inscriptions chrétiennes de la Gaule antérieures au VIII siècle, t. I, Paris, 1856, p. $105, \mathrm{n}^{\circ} 48$.

40. Corpus des inscriptions de la France médiévale (sera abrégé : C.I.F.M.), R. Favreau, B. Leplant-Mora, J. Michaud (éd.), 5, Poitiers, 1979, p. 110.

41. R. Favreau, "La table d'or" de la cathédrale de Sens », Bulletin de la Société des fouilles et monuments historiques de l'Yonne 18, 2001, p. 3.

42. N. Stratford, Catalogue of Medieval Enamels in the Bristish Museum. II. Northern Romanesque Enamels, Londres, 1993, fig. 192.

43. Patrologie latine, t. 20, c. 21.

44. Dans Venanzio Fortunato tra Italia e Francia, Atti del Convegno internazionale di Studi, Valdobbiadene, 1990, Trévise, 1993, p. 161-173 et réimpr. R. Favreau, Études d'épigraphie médiévale, I, Limoges, 1995, p. 531-546 ; voir aussi R. Favreau, " La mémoire du passé... », art. cit. (n. 7), p. 969-970. 
exemples. L'épitaphe de l'évêque de Plaisance, Podon, mort en 839, intègre quatre vers de l'épitaphe de Tetricus, évêque de Langres par Fortunat. Les deux premiers vers de l'épitaphe composée par Fortunat pour saint Victorien sont repris par Théodulphe d'Orléans avec changement de la syllabe initiale, et commencent au $\mathrm{XI}^{\mathrm{e}}$ siècle l'épitaphe du saint évêque de Nevers, Eulade, avec changement du premier mot du deuxième vers. Le premier vers de cette même épitaphe de saint Victorien est remployé tel quel en tête de l'épitaphe de Crescentius à Saints-Côme-et-Damien à Rome en 1010. Le premier vers de l'épitaphe de l'archevêque de Sens Mainard, en 1062 :

CARUS AMOR REGUM PATRIAE DECUS ARMA PARENTUM

«Amour chéri des rois, parure de la patrie, soutien de ses parents »

est évidemment calqué sur un vers de l'épitaphe de Tetricus évêque de Langres :

Summus amor regum, populi decus, arma parentum

et sur le soixante-et-onzième vers d'une composition métrique de Fortunat « sur le duc Loup » :

Principis auxilium, patriae decus, arma parentum.

Dans l'épitaphe bénéventine de Rofrit au IX ${ }^{\mathrm{e}}$ s. le paradisiacas epulas et le pro magnis parva susurro sont des remplois évidents d'expressions de Fortunat, et l'on pourrait, pour de simples expressions, multiplier les exemples.

Si on a reconnu dans les fragments d'une inscription provençale du musée Borély de Marseille les cinq premiers vers d'un poème d'Eugène, évêque de Tolède de 646 à 657, sans doute pour une église de Saragosse, les carmina d'Eugène de Tolède ont été surtout utilisés dans les inscriptions d'Espagne. L'épitaphe de Teresa, fille de Bermudo II et femme d'Abdalla, roi de Tolède, puis religieuse et abbesse du monastère San Pelayo d'Oviedo, est composée à partir des épitaphes d'Eugène pour l'évêque d'Orense Isaurus, de Basilla, $\mathrm{du}$ roi Chindesvintus, et des Quaerimoniae aegritudinis propriae du même Eugène. On retrouve au Musée de la cathédrale de Chiusi dans une inscription les vers 1 et 2, 5 et 6 de l'épitaphe de Basilla par Eugène. J'ai développé l'exemple d'Eugène de Tolède dans l'ouvrage que j'ai écrit sur l'Épigraphie médiévale ${ }^{45}$.

45. Collection L'atelier du médiéviste, 5, dirigée par J. Berlioz et O. Guyotjeannin, Turnhout, 1997, p. 150-152. Pour Chiusi : P. Rugo, Le iscrizioni dei secoli VI-VII-VIII esistenti in Italia. III. 
Alcuin a beaucoup écrit, s'est beaucoup répété, a beaucoup emprunté et a été beaucoup utilisé. J'ai montré en 1998 que l'anathème en deux vers qu'il a introduit dans l'épitaphe qu'il a rédigée pour lui-même, se trouvait aussi sur une ardoise conservée au musée Dobrée à $\mathrm{Nantes}^{46}$. Il est bien connu que dans les vingt-deux vers de l'épitaphe de l'archidiacre Pacificus de Vérone, mort en 846, sont copiés dix-neuf des vingt-quatre vers de l'épitaphe d'Alcuin. Le nunc cinis et pulvis (voir Genèse 18,27) de l'épitaphe d'Alcuin est aussi dans l'épitaphe d'Ogo, abbé de Saint-Maximin de Trèves puis évêque de Liège en 947, dans l'épitaphe du moine Ardo ( $\mathrm{X}^{\mathrm{e}}$ siècle ?), dans l'épitaphe de Crescentius à Rome en 1010, dans une autre épitaphe à Lüneburg en $1011^{47}$. Le quod nunc ego sum, tuque futurus eris de l'épitaphe d'Alcuin a quelque résonance dans l'épitaphe d'Ardo : quod nunc sum eris ipse futurus et de Crescentius, quodque futurus eris. Dans l'épitaphe célèbre du pape Hadrien à Saint-Pierre-du-Vatican (795) Alcuin dit le pape « large pour les pauvres, second à personne en piété $»$ :

\section{PAUPERIBUS LARGUS NULLI PIETATE SECUNDUS.}

On a déjà pauperibus largus dans l'épitaphe du pape Felix IV à Saint-Pierre en $530^{48}$. L'expression qui est aussi dans Fortunat est reprise pour l'épitaphe du pape Hadrien II en 872, se trouve à Saint-Ambroise de Milan en 956, à Lausanne en 1037, à Correns (Var) mi-XI ${ }^{\mathrm{e}}$ siècle, à Coimbra en 1162, au Mont-Saint-Eloi (Pas-de-Calais) en 1248, à Notre-Dame-aux-Nonnains à Troyes en 1264, à Saint-Jean-de-Latran en 1287. Alcuin a peut-être emprunté à l'Énéide de Virgile le nulli pietate secundus, qu'on retrouve après lui à Saint-Arnoul de Metz pour Louis le Pieux en 840, à Bonn pour l'évêque Folcmar en 965-969, à Saint-Mathias de Trèves au début du $\mathrm{XI}^{\mathrm{e}}$ siècle, à Saint-Remi de Reims en 1021, à Saint-Ouen de Rouen vers 1128, à Saint-Père de Chartres en 1231, à Molesmes en 1298, aux Jacobins de Chartres en 1276. Cécile Treffort a montré que l'épitaphe sur ardoise de l'abbé Ato à Angers en 835 était fortement inspirée du poème de l'Église d'York composé par Alcuin et a

46. R. Favreau, « La mémoire du passé... », art. cit. (n. 7), p. 969-970.

47. Poetae latini aevi carolini, 1, p. 350-351 (épitaphe d'Alcuin), 5, p. 316-317, p. 342, 6-1, p. 140-141; Die Deutschen Inschriften, 24, p. 3, n 1 et 70, p. 79, $\mathrm{n}^{\circ} 42$.

48. Le Liber pontificalis, L. Duchesne (éd.), 1, Paris, p. 280. 
étudié de façon plus générale « la place d'Alcuin dans la rédaction épigraphique carolingienne $»^{49}$.

S'il faudrait parler de Micon de Saint-Riquier, de Raban Maur, de Foulcoie de Beauvais, de Baudri de Bourgueil et de bien d'autres, le versificator par excellence pour les auteurs du XII siècle est Hildebert de Lavardin, avec la difficulté de ce qu'on lui a beaucoup attribué, en raison même de sa renommée. Le cum pietate gravis cum gravitate pius de l'épitaphe d'un probe homme ${ }^{50}$ est repris dans l'épitaphe de Burchard, évêque de Meaux, en 1134, à Saint-Victor de Paris ${ }^{51}$, et dans l'épitaphe que Simon Chèvre d'Or, chanoine de Saint-Victor, consacre à l'abbé Suger ${ }^{52}$. Le symbolisme de l'autel est mis en vers par Hildebert dans le De mysterio missae:

\section{Ara crucis tumulique calix, lapidisque patena \\ Syndonis officium candida byssus habet \\ « L'autel tient lieu de la croix, le calice du tombeau, \\ la patène de la pierre, le lin blanc du suaire ».}

Le distique est inscrit sur un autel portatif de Sainte-Marie-auCapitole de Cologne, l'a été sur un autel portatif, disparu, de La Souterraine en Limousin, également du XII siècle, et on le lit sur la patène trouvée dans la tombe de l'archevêque de Cantorbéry Hubert Walter mort en 1205. Le distique est cité dans une lettre de Geoffroy, sous-prieur de Sainte-Barbe, et dans le Mitrale de Sicard, évêque de Crémone ${ }^{53}$.

Le distique sur le Christ parlant de lui-même :

Pontus, terra, polus mihi subditur rex ego solus

Solus ab eterno creo cuncta creata guberno.

«Mer, terre, ciel me sont soumis, je suis le seul roi,

Seul de toute éternité je crée tout, je gouverne ce qui est créé. $»^{54}$

est gravé sur la châsse de Notre-Dame en la cathédrale d'Aix, le premier vers l'est sur le tympan roman de l'Ile-Barbe ${ }^{55}$, le second

49. Dans Alcuin, de York à Tours. Écriture, pouvoir et réseaux dans l'Europe du Haut Moyen $\hat{A} g e, \mathrm{Ph}$. Depreux et B. Judic (dir.), Rennes/Tours, 2004 (Annales de Bretagne et des pays de l'Ouest, t. 111), p. 355-369; «Un témoin de la vie publique et culturelle carolingienne à Angers : l'épitaphe sur ardoise de l'abbé Ato († 835) ", à paraître dans Actes du colloque l'Anjou au Haut Moyen Âge.

50. Patrologie latine, t. 171 , c. 1394

51. Gallia christiana, VIII, c. 1612.

52. Histoire littéraire de la France, 112, c. 374-375

53. R. Favreau, «Les autels portatifs et leurs inscriptions », Cahiers de civilisation médiévale 46, 2003, p. 348-349.

54. Patrologie latine, t. 171, c. $1436, \mathrm{n}^{\circ} \mathrm{CXX}$, Christus de se ipso.

55. R. Favreau, «Un tympan roman à l'Ile-Barbe près de Lyon », Comptes rendus des séances de l'Académie des Inscriptions et Belles-Lettres, 2005, p. 1016-1017. 
vers l'est sur la châsse de saint Remacle de Stavelot au XIII ${ }^{\mathrm{e}}$ siècle et il inspire un distique de la « table d'or » de la cathédrale de Sens.

Pierre Comestor ou Le Mangeur, doyen de l'église de Troyes, mort à Saint-Victor de Paris vers 1179, avait composé son épitaphe :

Petrus eram quem petra tegit dictusque Comestor ${ }^{56}$.

Elle a été insérée dans une collection de poésies médiévales de la fin du XII ${ }^{\mathrm{e}}$ siècle conservée à Copenhague ${ }^{57}$. Le Quem petra tegit se trouve à Coimbra en $1281^{58}$, à Trouville-sur-Pont-Audemer au $\mathrm{XIII}^{\mathrm{e}}$ siècle, à Saint-Denis vers 1300 . On voit combien il faut être attentif à ces auteurs médiévaux qui manient les vers avec aisance et que l'on copie facilement. Et si l'on note que l'épitaphe de Pierre Comestor a été recopiée dans la Chronique de Robert chanoine de Saint-Marien d'Auxerre ${ }^{59}$, on voit que les textes circulent aussi, non seulement par les œuvres mêmes ou par des anthologies, mais par les chroniqueurs, les auteurs de Vitae, d'Histoires d'abbayes, qui ont compris dans leurs œuvres beaucoup d'inscriptions.

\section{Chroniques, biographies, histoires}

Il est d'autant plus utile de scruter les œuvres des chroniqueurs, biographes, historiens d'abbayes qu'elles nous fournissent beaucoup d'inscriptions aujourd'hui disparues, avec leur contexte historique et souvent de précieux détails de localisation ou décoration. En circulant ces œuvres devenaient aussi des sources d'inspiration pour ceux qui avaient à composer des inscriptions. Les chroniqueurs de Saint-Benoît-sur-Loire, Helgaud, Abbon et Gauzlin de Fleury, ont permis à Robert-Henri Bautier de présenter le monastère et les églises de Fleury de 988 à 1032, avec une part importante aux inscriptions : devant d'autel de l'église Notre-Dame, fresques de l'Apocalypse (vingt et une scènes) et de la vie et des miracles de saint Pierre (quatorze scènes) en l'église Saint-Pierre, réfectoire avec les fresques des fables de Phèdre, trésor de l'abbaye ${ }^{60}$. La Chronique

56. Gallia christiana, XII, c. 525 .

57. Patrologie latine, t. 198 , col. 1048

58. Pour les inscriptions médiévales du Portugal il faut se reporter à la thèse de M. J. Barroca, Epigrafia medieval portuguesa (862-1422), parue en 2000, ici le vol. II Corpus epigráfia medieval portugués, t. I, 395, p. 1011-1015.

59. Monumenta Germaniae Historica. Scriptores, t. 26, p. 242.

60. R.-H. Bautier, « Le monastère et les églises de Fleury-sur-Loire sous les abbatiats d'Abbon, de Gauzlin et d'Arnaud 988-1032 », Mémoires de la Société nationale des Antiquaires de France, $9^{\mathrm{e}}$ s., t. IV, 1969, p. 71-153. 
de l'abbaye de Saint-Riquier (V siècle-1104), d'Hariulf nous a gardé une série d'inscriptions ${ }^{61}$ notamment sur l'abbé Angilbert. L'inscription du tombeau de celui-ci bâtie sur les mots REX LEX LUX PAX a inspiré nombre d'autres inscriptions ${ }^{62}$. Le quem tegit hic tumulus de l'abbé Angelrannus se retrouve au XII ${ }^{\mathrm{e}}$ siècle à Agen (Musée), à La Daurade de Toulouse. S'il ne reste rien de l'église de l'abbé Didier, la Chronique du Mont-Cassin dit qu' « il fit couvrir l'abside et l'arc majeur de mosaïque, sur le pourtour de laquelle il fit écrire en lettres d'or ces vers $\gg{ }^{63}$ :

\title{
UT DUCE TE PATRIA JUSTIS POTIATUR ADEPTA HINC DESIDERIUS PATER HANC TIBI CONDIDIT AULAM, «Pour que sous ta direction les justes obtiennent la vraie patrie, l'abbé Didier a fondé pour toi cette église ».
}

qui imitent le distique placé par Constantin sur l'arc triomphal de la basilique qu'il avait fait construire sur le tombeau de saint Pierre au Vatican ${ }^{64}$ :

\section{QUOD DUCE TE MUNDUS SURREXIT IN ASTRA TRIUMPHANS HANC CONSTANTINUS VICTOR TIBI CONDIDIT AULAM, \\ «Puisque sous ta direction, le monde s'est levé triomphant vers les cieux, Constantin, victorieux, a fondé pour toi cette église».}

On notera que si on a de nombreux exemples épigraphiques d'un TE DUCE cité dans Horace, Virgile, Augustin, Cœlius Sedulius, la forme DUCE TE semble ne se trouver qu'à Rome et au MontCassin. La même chronique du Mont-Cassin cite à la suite quatre vers inscrits par l'abbé Didier dans l'abside de son abbatiale au $\mathrm{XI}^{\mathrm{e}}$ siècle :

\author{
HAEC DOMUS EST SIMILIS SYNAI SACRA JURA FERENTIS \\ UT LEX DEMONSTRAT HIC QUAE FUIT EDITA QUONDAM \\ LEX HINC EXIVIT MENTES QUAE DUCIT AB IMIS \\ ET VULGATA DEDIT LUMEN PER CLIMATA SECLI.
}

61. R. Favreau, "Rex Lex Lux Pax. Jeux de mots et jeux de lettres dans les inscriptions médiévales ", Bibliothèque de l'École des Chartes, t. 161, 2003, p. 625-635.

62. Éditée par Ferdinand Lot, Paris, 1884 (Collection des textes pour servir à l'enseignement de l'histoire), p. 55, 73-76, 78, 103, 202, 206, 210, 274.

63. Chronicon monasterii Casinensis auctore Leone, W. Wattenbach (éd.), MGH, Scriptores, VII, 1846, p. 28.

64. J.-B. de Rossi, Inscriptiones christianae urbis Romae septimo saeculo antiquiores, II-1, Rome, 1888 , p. $20,123,341,345,410$. 
Ces quatre vers sont copiés sans changement sur une inscription de l'abside de Saint-Jean-de-Latran qui serait due au pape Serge III (904-911) ${ }^{65}$.

L'épitaphe de l'évêque Reginard (†1030) par l'abbé de SaintLaurent de Liège Everelmus, transmise par la Vita Reginardi de Renier, moine de Saint-Laurent de Liège :

\section{FLOS DECUS ECCLESIAE PRAESUL SPECULUMQUE SOPHIAE ${ }^{66}$}

a peut-être inspiré l'auteur de l'épitaphe de l'évêque Reginald $(\dagger 1283)$ en la cathédrale de Beauvais :

\section{HIC DECUS ECCLESIAE REGINALDUS GEMMA SOPHIAE ${ }^{67}$.}

Il faudrait une étude particulière sur Orderic Vital qui nous rapporte pas moins d'une trentaine d'épitaphes, dont sept ont été composées par lui-même. L'abbé Suger nous donne les vers qu'il a composés pour l'antependium d'or, le tombeau des corps saints, le maître-autel, les vitraux, les vases de son abbaye de Saint-Denis ${ }^{68}$, mais c'est un auteur très personnel, qui emprunte peu à des sources épigraphiques et a été peu copié. Dans les divers ouvrages historiques de Guillaume, moine de Malmesbury, on trouvera plusieurs épitaphes et des inscriptions sur des orgues, un vase, un reliquaire, et l'épitaphe d'Henri II Plantagenêt à Fontevraud n'est connu que par trois chroniqueurs anglais, Raoul de Dicet, Roger de Wendower et Matthieu Paris ${ }^{69}$. Cette pratique d'insérer des inscriptions dans des ouvrages historiques sera reprise à partir de la fin du XVI ${ }^{\mathrm{e}}$ siècle, et du début du XVII ${ }^{\mathrm{e}}$ avec les Annales ecclesiastici du cardinal César Baronius que poursuivra Mansi au XVIII ${ }^{\mathrm{e}}$ siècle (25 volumes), la Cronica general de la orden de San Benito par Fra Antonio de Yepes ou les Annales d'Angel Manrique pour l'ordre cistercien ${ }^{70}$. Il y a là

65. Ibid., p. 149 et 306 ; Ph. Lauer, Le palais de Latran. Étude historique et archéologique, Paris, 1911, p. 138. L'inscription été détruite lors des restaurations de l'abside de Saint-Jean-deLatran par Nicolas IV en 1291.

66. Éditée par W. Arndt, MGH, Scriptores, XX, Hanovre, 1868, p. 578.

67. Gallia christiana, IX, c. 747-748.

68. Suger, Euvres. T. I. Écrit sur la consécration de Saint-Denis. L'œuvre administrative. Histoire de Louis VII, Fr. Gasparri (éd. et trad), Paris, 1996 (Les classiques de l'Histoire de France au Moyen Âge, 37).

69. R. Favreau, « L'épitaphe d Henri II Plantagenet à Fontevraud », Cahiers de civilisation médiévale 50, 2007, p. 3-10.

70. E. Martín López, « Les inscriptions médiévales dans les Annales de Manrique : contribution à la possibilité d'une épigraphie cistercienne », Cahiers de civilisation médiévale 52, 2009, p. 395-413. 
et dans les grandes œuvres des bénédictins et des jésuites des XVII et $\mathrm{XVIII}^{\mathrm{e}}$ siècles un ample champ à explorer pour l'épigraphie.

\section{Sylloges, épitaphiers}

Les recueils d'inscriptions, sylloges, épitaphiers, auxquels on peut joindre les rouleaux des morts, ont permis une large circulation des textes. Jean-Baptiste de Rossi l'avait bien compris qui a consacré le second volume de ses Inscriptiones urbis Romae septimo saeculo antiquiores (Rome, 1888), à la publication de sylloges épigraphiques, soit plus de six cents textes disséminés dans soixante-six recueils ${ }^{71}$.

Les églises de Rome ont la première place dans les sylloges. J'ai précédemment cité deux inscriptions de Saint-Pierre-du-Vatican et de Saint-Jean-de-Latran qui se retrouvent au Mont-Cassin. Quatre vers étaient inscrits sur la première mosaïque de l'abside de Saint-Pierre-du-Vatican :

\section{JUSTITIAE SEDES FIDEI DOMUS AULA PUDORIS HAEC EST QUAM CERNIS PIETAS QUAM POSSIDET OMNIS QUAE PATRIS ET FILII VIRTUTIBUS INCLYTA GAUDET AUCTOREM SUUM GENITORIS LAUDIBUS AEQUAT ${ }^{72}$ \\ «Cette [église] que tu vois est siège de la justice, maison de foi, demeure d'honneur. Toute piété l'habite. Elle se réjouit d'être illustrée par les vertus du Père et du Fils. En louant la Mère elle rend aussi honneur à son Auteur ».}

Le premier vers a été repris dans l'église Saint-Agapit de Rome au $\mathrm{IV}^{\mathrm{e}}$ siècle $^{73}$, et les quatre vers ont été inscrits au VI siècle à Henschir Adjedj près de Tébessa en Algérie ${ }^{74}$. Le premier vers est aussi dans une lettre du pape Hadrien Ir $^{\text {er }}$ Charlemagne au sujet du culte des images $^{75}$. Une inscription de Saint-Pierre-aux-Liens de Rome du temps du pape Sixte III (432-440) :

71. Dom H. Leclercq, « Inscriptions (Histoire des recueils d'), », Dictionnaire d'archéologie chrétienne et de liturgie, VII-1, 1926, col. 850-1089 ; J.-B. de Rossi, ibid., XVI-1, 1950, c. 35-42 (les sylloges épigraphiques), « Sylloges », ibid., XV-2, 1953, c. 1755-1756.

72. J.-B. de Rossi, op. cit. n. précédente, II-1, p. 21, 47, 55, 145, 156, 341 ; G. Curzi, « La decoratione musica della basilica dei SS. Nereo e Achilleo in Roma : matriali ed ipotesi ", Arte medievale, $2^{\mathrm{e}}$ s. anno VI, n. 21, 1993, p. 37, fig. 26.

73. Le Liber pontificalis, L. Duchesne (éd.), II, p. 40.

74. Inscriptiones Africae latinae. Pars posterior. Incriptiones Mauretaniarum, G. Wilmanns (éd.), Berlin, 1881 (C.I.L., VIII-2), p. 947, n 10698

75. Sacrorum conciliorum nova et amplissima collectio, par J.-D. Mansi, XIII, Florence, 1767, col. 774 . 


\begin{abstract}
CEDE PRIUS NOMEN NOVITATI CEDE VETUSTAS REGIA LETANTER VOTA DICARE LIBET

HAEC PETRI PAULIQUE SIMUL NUNC NOMINE SIGNO

XYSTUS APOSTOLICAE SEDIS HONORE FRUENS

UNUM QUAESO PARES, UNUM DUO SUMITE MUNUS

UNUS MONOR CELEBRAT QUOS HABET UNA FIDES

PRESBITERI TAMEN HIC LABOR EST ET CURA PHILIPPI... ${ }^{76}$
\end{abstract}

a été copiée avec quelques changements dans l'Afrique romaine, à Aïn Ghorab :

CEDE PRIUS NOMEN NOVITATI CEDE VETUSTAS
REGIA LETANTER VOTO DICARE LIBET
HAC PETRI PAULIQUE SEDES CRISTO JUBENTE RESURGIT ${ }^{77}$

et :

UNUM QUESO PARES UNUM DUO SUMITE MUNUS

AECLESIA UNUS HONOR CELEBRET QUOS HABET UNA FIDES

DOM. PRESBYTERI TAMEN HIC OPUS EST ET CURA PROBANTI ${ }^{78}$.

Les six vers de l'épitaphe que le pape Damase composa pour luimême :

QUI GRADIENS PELAGI FLUCTUS COMPRESSIT AMAROS

VIVERE QUI PRAESTAT MORIENTIA SEMINA TERRE

SOLVERE QUI POTUIT LETALIA VINCULA MORTIS

POST TENEBRAS FRATREM POST TERTIA LUMINA SOLIS

AD SUPEROS ITERUM MARTAE DONARE SORORI

POST CINERES DAMASUM FACIET QUIA SURGERE CREDO ${ }^{79}$

ont été repris au IX ${ }^{\mathrm{e}} \mathrm{S}$. ( ?), à Saint-Maximin de Trèves en remplaçant DAMASUM par ERICUM ${ }^{80}$. À Saint-Mathias de Trèves on a de même copié en 1002 les quatre premiers vers de l'épitaphe d'Angilbert, abbé de Saint-Riquier, par le diacre Micon, en remplaçant Angilbertus par Engelbertus, ici avec les mêmes prénoms ${ }^{81}$. Le vincula mortis de l'épitaphe de Damase se retrouve dans une inscription chrétienne du Musée de Latran, à Saint-Denis, au tympan de

76. J.-B. de Rossi, op. cit. (n. 71), II-1, p. 110 et 134 ; E. Diehl, op. cit. (n. 11), I, p. 182, n 974.

77. Inscriptiones Africae latinae..., G. Wilmanns (éd.) (CIL, VIII-2), p. 948, n 10707.

78. Ibid., $\mathrm{n}^{\circ} 10708$.

79. J.-B. de Rossi, op. cit. (n. 71), II-1, p. 252, 287 ; Poetae latini aevi carolini, E. Duemmler (éd.), MGH, Poetae latini, I, Berlin, 1881, p. 557 ; E. Diehl, Inscriptiones latinae christianae veteres, I, 1925 , p. $180, \mathrm{n}^{\circ} 963$.

80. Die Inschriften der Stadt Trier I (bis 1500), R. Fuchs (éd.), Wiesbaden, 2006 (Die Deutschen Inschriften, 70), p. 61-64, $\mathrm{n}^{\circ} 34$.

81. Ibid., p. $142, \mathrm{n}^{\circ} 69$; Louis Traube, MGH, Poetae latini, III, Berlin, 1896, p. 314, ${ }^{\circ} 45$. 
Petershausen (Musée de Karlsruhe), dans un vitrail de Cantorbéry dans plusieurs rouleaux des morts. Le surgere credo final est dans l'épitaphe carolingienne d'Eigil à Fulda, dans une épitaphe carolingienne du Musée de Pavie - quia surgere credo - qui imite dans son premier vers, qui mare gradiens undas planavit tumentes, le premier vers de Damase ${ }^{82}$.

Les seize vers de l'épitaphe de Grégoire le Grand (†604) figurent dix fois dans les sylloges réunis par J.-B. de Rossi ${ }^{83}$. Les deux premiers vers se trouvent dans une inscription de fin $\mathrm{VII}^{\mathrm{e}}-\mathrm{VIII}{ }^{\mathrm{e}}$ siècle à Pavie ${ }^{84}$, dans une épitaphe du Musée de Latran à Rome avec des déformations grossières ${ }^{85}$, les trois premiers vers sont à SaintMaximin de Metz, dans le tombeau de saint Urbicius, avec des fautes qui en rendent la lecture pour partie incompréhensible ${ }^{86}$. Les seize vers sont repris dans une inscription $\mathrm{du}_{\mathrm{IX}}^{\mathrm{e}}$ siècle à la cathédrale de Nepi, avec quelques fautes et surtout le remplacement de pontificis par episcopus au cinquième vers, ce qui donne un surprenant episcopus summi ${ }^{87}$ et on a gardé le onzième vers qui rappelle l'action de Grégoire $\mathrm{I}^{\mathrm{er}}$ pour la conversion des Anglais. Le clauduntur membra sepulcro de ce même cinquième vers est employé par Arnoul, évêque de Lisieux, pour l'épitaphe d'Hugues III, archevêque de Rouen, mort en $1164^{88}$. Une inscription de dix vers à l'hôpital Saint-Pierre de Rome fondé par Léon III (795-816) ${ }^{89}$, se trouvait dans l'ancienne abbatiale de Condom, d'après des copies du XIV ${ }^{\mathrm{e}}$ siècle et de 1668, avec de menus changements aux sixième, septième et huitième vers, un changement plus important au dixième vers ${ }^{90}$.

82. G. Panazza, «Lapidi e sculture paleocristiane e pre-romanische di Pavia », Arte del primo millenio..., Turin, 1950 , p. $272, \mathrm{n}^{\circ} 89$.

83. J.-B. de Rossi, op. cit. (n. 71), II-1, p. 52, 78-79, 112, 166, 209, 253, 266, 275, 278, 299. L'épitaphe se trouve dans la Vie de Grégoire écrite par le diacre romain Jean au IX siècle (Acta sanctorum, Mars, 2, p. 200). Elle figure aussi dans un florilegium du IX siècle, le ms. latin 2832, fol. $115 \mathrm{v}^{\circ}-116$ de la BnF.

84. G. Panazza, op. cit. (n. 82), p. 249, avec fautes (tuum au lieu de tuo, quo au lieu de quod, vivificanti au lieu de vivificante.

85. A. Silvagni, Monumenta epigraphica christiana saeculo XIII antiquiora quae in Italiae finibus exstant. I. Roma, Cité du Vatican, 1943, pl. XXXVI-8.

86. Die christlichen Inschriften der Rheinlande von der mitte des achten bis zur mitte des dreizehnten Jahrhunderts, F. X. Kraus (éd.), Friburg et Leipzig, 1894, p. 154, nº 314. L'identification de la source a été faite par Edmond Le Blant, Bulletin de la Société nationale des antiquaires de France, 1867, p. 48-49.

87. Inscriptiones Medii Aevi Italiae (saec. VI-XII). Lazio. Viterbo, 1, Spolète, 2002, p. 79-82.

88. C.I.F.M., 22, Paris, 2002, p. 288. L'expression est aussi dans un florilège du IX' $\mathrm{s}$. (BnF, ms. lat. 2832 , f. $\left.115 \mathrm{v}^{\circ}-116\right)$.

89. J.-B. de Rossi, op. cit. (n. 71), II-1, p. 47 ; Le Liber pontificalis, II, p. 47.

90. C.I.F.M., 6, Paris, 1981, p. 40-42. 
La basilique Saint-Martin de Tours a été, avec les sanctuaires de Rome, un des lieux de pèlerinage les plus fréquentés, et dès le $\mathrm{VII}^{\mathrm{e}}$ siècle une sylloge rapporte les inscriptions de la basilique ${ }^{91}$. Dix vers de Saint-Martin ont été reproduits dans une inscription de Saint-Étienne de Rome en changeant aux vers 4 et 8 Martinus et Martinum en Stephanus et Stephanum ${ }^{92}$. Louis Duchesne suggère que l'église de Rome pourrait être Saint-Étienne Mineur fondé par le pape Étienne II, lequel vint en France solliciter l'appui de Pépin le Bref contre les Lombards. Au tympan de Mozac en Auvergne on a recopié le premier vers d'une inscription placée à Saint-Martin à l'est $\left(\mathrm{n}^{\circ} 5\right.$ de la sylloge) et le premier vers d'une autre inscription placée d'un autre côté ( ${ }^{\circ} 6$ de la sylloge), comme s'il s'agissait d'un texte suivi de part et d'autre d'une entrée. Du coup, pour se trouver en concordance avec le premier vers, ingrediens templum, « que celui qui entre dans l'église », on a changé au second vers venerantes en venerans, mais on a laissé inchangé le pluriel intraturi ${ }^{93}$.

Après la prise de Jérusalem par les croisés en 1099 des sanctuaires chrétiens furent bâtis partout en Terre Sainte. Foucher de Chartres $(\dagger 1128)$ a écrit une Historia Jherosolymitana. Gesta Francorum peregrinantium ab anno Domini MXCV usque ad annum MCXXVII, où, à plusieurs reprises, il interrompt son récit en prose pour joindre des vers de sa composition. Ainsi fait-il en vers mémoire de la prise de Jérusalem au chapitre XXX :

\section{Anno milleno centeno quominus uno \\ Virginis a partu Domini qui claruit ortu \\ Quindecies julio jam Phoebi lumine tacto \\ Jherusalem Franci capiunt virtute potenti \\ Quippe Godefrido patriae mox principe facto ${ }^{94}$.}

Les vers 1, 3 et 4 ont été gravés sur une porte de bronze de la basilique du Saint-Sépulcre, les vers 1-4 le furent sur un sarcophage près de la basilique ${ }^{95}$. En 1165 Jean de Wirzburg a transcrit dans sa Descriptio Terrae Sanctae, une quarantaine d'inscriptions qu'il avait

91. F. J. Gilardy, The Sylloge Epigraphica Turonensis de Sancto Martino, Washington, 1983 ; Luce Pietri, La ville de Tours du $I V^{e}$ au VI $I^{e}$ siècle : naissance d'une cité chrétienne, Rome, 1983, p. 804 .

92. J.-B. de Rossi, II-1, p. 275, n 19-20 ; Le Liber pontificalis, L. Duchesne (éd.), II, p. $460-461$

93. C.I.F.M., 18, Paris, 1995 , p. $222-223$

94. Recueil des historiens des croisades. Historiens occidentaux, t. III, Paris, 1856, p. 361. Dans ses vers Foucher cite sans cesse Phœbus.

95. S. de Sandoli, Corpus inscriptionum crucesignatorum Terrae Sanctae (1099-1291), Jérusalem, 1974, p. 63, nº 73 et p. $66, n^{\circ} 76$. 
vues à Jérusalem et à Bethléem, dont les deux inscriptions ci-dessus. On comprend mieux dès lors comment on a pu inscrire en 1156 les quatre premiers vers de Foucher dans la petite église ariégeoise de Daumazan-sur-Arize ${ }^{96}$, soit qu'un pèlerin les ait copiés à Jérusalem, soit qu'on ait connu dans la région de Daumazan le récit de Foucher de Chartres. Autour du tympan de l'église de Corneilla-de-Conflent en Roussillon au centre duquel trône la Vierge tenant l'Enfant sur ses genoux on a inscrit, dans la seconde moitié du XII ${ }^{\mathrm{e}}$ siècle, un distique :

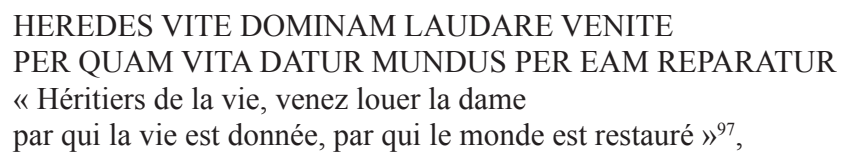

qui se lisait à l'entrée de l'église souterraine du Tombeau de la Vierge à Jérusalem ${ }^{98}$. Là aussi un pèlerin ou un croisé peut 1'avoir recopié à Jérusalem, mais le texte a pu aussi être pris dans la Description de la Terre Sainte de Jean de Wirzburg, qui date de 1165.

Les rouleaux des morts, sur lesquels la publication de Léopold Delisle en 1866 a attiré l'attention, et dont un recueil général est en cours de publication par les soins de Jean Dufour, ne peuvent être ignorés par l'épigraphiste, tant il y trouve des expressions, des vers qu'il rencontre aussi dans les inscriptions. Diffuseurs, emprunteurs, leur part est difficile à apprécier. Je ne retiendrai que deux exemples.

C'est dans le rouleau mortuaire de Bernat, abbé de Ripoll († 1102) que j'ai rencontré pour la première fois l'expression ad mala tardus, inscrite sur le rouleau à San Pedro de Jaca :

Abbas Bernardus vivens fuit ad mala tardus ${ }^{99}$.

Sur une épitaphe de San Miguel de Escalada en 1169 on lit :

Fuit hic satis ad mala tardus ${ }^{100}$.

96. C.I.F.M., 8, Paris, 1986, p. 48-49.

97. C.I.F.M., 11, Paris, 1986, p. 48-49.

98. S. de Sandoli, op. cit. (n. 95), p. 177, n 239 ; J. de Wurtzbourg, Descriptio terrae Sanctae, S. de Sandoli (éd.), Itinera Hierosolymitana Crucesignatorum saec. XII-XIII. II. Tempora regum Francorum (1100-1187), Jérusalem, 1980, p. 274.

99. J. Dufour, Recueil des rouleaux des morts : VIII siècle-vers 1536, t. I. VIII siècle-1180, Paris, 2005 (Recueil des historiens de la France publié par l'Académie des Inscriptions et Belles-Lettres. Obituaires, série in $4^{\circ}$, t. VIII), p. 270, n ${ }^{\circ} 104$.

100. V. Garcia Lobo, Las inscripciones de San Miguel de Escalada. Estudio crítico, Barcelone, 1982, p. $74, n^{\circ} 17$. 
L'épitaphe de l'abbé Bernard II à Savigny vers 1173 le dit :

Moribus inclitus atque bonus vir ad mala tardus ${ }^{101}$.

et celle de Rodrigue, archevêque de Tolède, à Santa Maria de Huesta en 1247 emploie encore la même formule en fin de vers ${ }^{102}$.

Le vers écrit à Saint-Étienne de Fontenay au diocèse de Bayeux sur le rouleau mortuaire de Mathilde, abbesse de la Trinité de Caen, morte en 1113 :

Mundi Salvator animae sis ejus amator

se retrouve tel quel dans l'épitaphe de Bernard de Roquefeuil à Saint-Guilhem-le-Désert en $1248^{103}$.

\section{Florilèges, sentences, proverbes}

De nombreux manuscrits comportent des anthologies de compositions métriques, souvent des distiques, sur des sujets variés, épitaphes, proverbes, poèmes eucharistiques, etc. Leur circulation entre les diverses bibliothèques peut expliquer que l'on trouve la même inscription en des lieux très différents. Seule une étude générale de ces anthologies permettrait d'en rendre compte de façon précise. Le recueil de poésies médio-latines de la fin du XII ${ }^{\mathrm{e}}$ siècle analysé par Paul Lehmann en $1935^{104}$ en fournit un exemple. On y lit :

Rex obit, hec plorat, carus dolet, impius orat

Sol fugit, astra tremunt, pavet hostis, corpora surgunt.

et encore :

Hic obit, hec plorat, carus dolet, impius orat

Derogat hic, gemit hec, obit is, dolet hic, rogat iste ${ }^{105}$.

101. C.I.F.M., 17, Paris, 1994, p. 126.

102. J. Loperráez Corvalán, Descripcion histórica del obispado de Osma, I, Madrid, 1788, p. 204-205.

103. C.I.F.M., 12, Paris, 1988, p. 165.

104. P. Lehmann, "Eine Sammlung mittellateinischer Gedichte aus dem Ende des 12. Jahrhunderts », Historischen Vierteljahrsschrift XXX, 1935, p. 20-58, repris dans Erforschung des Mittelalters, Band IV, Stuttgart, 1961, p. 283-316.

105. Ibid., p. 288 
Le premier vers, accompagne une Descente de croix au tympan du portail du transept sud de la cathédrale de Ribe au Danemark ${ }^{106}$ : le roi meurt (le Christ), celle-ci pleure (la Vierge Marie), l'aimé se lamente (saint Jean), l'impie prie (le centurion). Le vers qui remplace seulement rex par hic est gravé au-dessus d'une Descente de croix au pilier nord-est du cloître de l'abbaye de Silos ${ }^{107}$. Cette identification des personnages par un vers se trouve aussi dans des Crucifixions, au dernier tiers du XII ${ }^{\mathrm{e}}$ siècle, à Paris et Bruxelles :

HEC PARIT, HEC CREDIT, OBIT HIC, FUGIT HEC, HIC OBEDIT

ou à la cathédrale de Trèves :

ISTA FLET, HEC SURGIT, OBIT HIC, CADIT HEC, DOLET ISTE

pour désigner Marie, l'Église, le Christ, la Synagogue, Jean ${ }^{108}$.

Dans ce même recueil conservé à la bibliothèque de l'université de Copenhague et provenant de l'abbaye bénédictine SS.-Cômeet-Damien de Liesborn en Westphalie, on trouve aussi un poème eucharistique :

Carnem quam gustas non atterit ullea venustas perpetuus cibus est, qui negat hoc reus est.

Hec caro quam comedis te salvat si bene credis

At male si credis, indicium comedis ${ }^{109}$.

Le texte a été recopié sans le bien comprendre et il faut corriger venustas en vetustas et indicium en judicium. Les deux premiers vers ont été gravés sur le calice de l'abbé Pélage aujourd'hui conservé à Paris, au musée du Louvre, avec des erreurs qui rendent le second vers incompréhensible, mais qu'on peut corriger en se reportant au manuscrit de Liesborn :

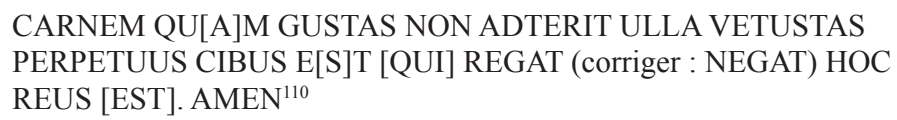

106. A. Anderson, L'art scandinave, 2, La Pierre-qui-Vire, 1968 (Zodiaque. La nuit des temps, 29), p. 53 , pl. 35.

107. Dom L.-M. de Logendio et dom A. Rodriguez, Castille romane, 2, La Pierre-qui-Vire, 1966 (Zodiaque. La nuit des temps, 24), p. 45 et pl. 5 ; photothèque du Centre d'études supérieures de civilisation médiévale.

108. Die Inschriften der Stadt Hildesheim, Chr. Wulf (éd.), Wiesbaden 2003 (Die Deutschen Inschriften, $58 »$, p. $269, \mathrm{n}^{\circ} 52$ et p. $272, \mathrm{n}^{\circ} 54$, fig. 33

109. P. Lehmann, op. cit. (n. 104), p. 291.

110. R. Favreau, "Les inscriptions du calice et de la patène de l'abbé Pélage au Louvre », Comptes rendus des séances de l'Académie des Inscriptions et Belles-Lettres, année 1993, p. 29-45. 
Le même recueil a transcrit l'épitaphe que Pierre le Mangeur (Comestor), mort vers 1179, avait composée pour lui-même à SaintVictor de Paris, et qui se termine par :

Quod sumus iste fuit, erimus quandoque quod hic est ${ }^{111}$.

Ce vers se lit dans une épitaphe de SS.-Silvestre-et-Martin « ai Monti » à Rome en $1296^{112}$.

Les ouvrages de littérature didactique, avec leurs maximes de bonne conduite, sont à la source de plusieurs inscriptions. Les Disticha de moribus nomine Catonis inscripta conseillent de prendre garde à l'adversité lorsqu'on aura été heureux :

Cum fueris felix quae sunt adversa caveto.

Le vers se trouve en 1164 dans une inscription de Santa Maria de Junquera de Ambia ${ }^{113}$. Dans le même ouvrage on peut lire :

Trocho lude, aleas fuge

Esbas ty a petit jeu honneste et fuy tous jeux de hazard.

On a inscrit sur le tailloir d'un chapiteau de Charlieu :

TROQUO LUDE, ALIAS FUGE ${ }^{114}$,

sans comprendre le mot aleas, dés, jeux de dés, jeux de hasard.

Le Facetus est un autre de ces auctores octo morales qui ont été très employés dans la formation scolaire du XI ${ }^{\mathrm{e}}$ siècle. Au Crac des chevaliers (Syrie) un distique invitait, au XIII ${ }^{\mathrm{e}}$ siècle les Hospitaliers de Saint-Jean-de-Jérusalem à fuir l'orgueil qui « souille tout ce qu'il approche, richesse, sagesse, beauté » :

SIT TIBI COPIA SIT SAPIENCIA FORMAQUE DETUR INQUINAT OMNIA SOLA SUPERBIA SI COMITETUR.

Ce distique est tiré du Facetus, reproduit dans le Speculum morale de Vincent de Beauvais, se trouvait curieusement en l'église SaintHippolyte de Poligny (Jura) sur un reliquaire de la Sainte-Épine, du $\mathrm{XV}^{\mathrm{e}}$ siècle, qui a disparu à la Révolution. La modification du second vers de Poligny sola superbia destruit omnia ${ }^{115}$, est aussi la forme de

111. Patrologie latine, t. 198 , col. 1048 .

112. V. Forcella, Iscrizioni delle chiese e d'altri edifici di Roma dal secolo XI ai giorni nostri, Rome, IV, 1874, p. 7, n 4.

113. España sagrada, 17, p. 91.

114. C.I.F.M., 18, Paris, 1995, p. 62

115. F. de Mély, « Reliques de Constantinople », Revue de l'art chrétien, 5érie, t. XI, 1900, p. 501 . 
ce même distique qu'Antoine de La Sale a introduit dans son roman du Petit Jehan de Saintré.

Du Facetus encore viennent deux vers qui invitent à honorer l'image du Christ mais à réserver l'adoration à Celui que représente l'image :

\section{Effigiem Christi qui transis semper honora non tamen effigiem sed quem designat adora.}

Ces deux vers sont inscrits sur un reliquaire phylactère à quatre lobes d'environ 1165, d'origine mosane, qui se trouve aujourd'hui au Musée de l'Ermitage à Saint-Pétersbourg, avec de légères modifications, dont une curieuse inversion des deux impératifs qui en modifie radicalement le sens :

\section{ESFIGIEM CHRISTI DUM TRANSIS PRONUS ADORA NON TAMEN EFFIGIEM SED QUEM DESIGNAT HONORA.}

Guillaume Durand a reproduit le distique dans son Rationale divinorum officiorum, et un auteur norvégien en a suivi la fortune aux $\mathrm{XV}^{\mathrm{e}}$ et $\mathrm{XVI}^{\mathrm{e}}$ siècles, avec des inscriptions sur une croix islandaise de 1406, un crucifix du XVI ${ }^{\mathrm{e}}$ siècle au Musée de Reykjavik, un autel portatif de 1554 au Musée de Copenhague ${ }^{116}$.

C'est probablement par les nombreux manuscrits ${ }^{117}$ qui le citent que le distique suivant a eu une large fortune en Occident :

$O$ dives, dives, non omni (ou : multo) tempore vives

Fac bene dum vivis, post mortem vivere si vis.

«O riche, riche, tu ne vivras pas tout le temps

fais le bien pendant que tu vis, si tu veux vivre après ta mort. »

On a déjà une partie du premier vers dans Wipo :

Ve tibi, ve dives, non omni tempore vives ${ }^{118}$.

Le distique se lit sur un chapiteau du cloître de Monreale en Sicile avec multo tempore ${ }^{119}$. On le lit aussi au XII ${ }^{\mathrm{e}}$ siècle sur le livre du

116. R. Bugge, «Effigiem Christi, qui transis, semper honora. Verses condemning the cult of sacred images in art and literature », Acta and archeologiam et artium historiam pertinentia, vol. VI, Rome, 1975 (Institutum Romanum Norvegiae), p. 130-133.

117. H. Walther, Initia carminum ac versuum Medii Aevi posterioris latinorum, I/1, Göttingen, p. 648, $\mathrm{n}^{\circ} 12601$; Proverbia sententiaeque latinitatis Medii Aevi, II/3, Göttingen, 1965, p. 522, $\mathrm{n}^{\circ} 19451$.

118. Die Werke Wipos, H. Bresslau (éd.), Hanovre et Leipizig, 1915 (M.G.H., Scriptores in usu scholarum, 61), p. 73.

119. R. Sabatini, Il chiostro di Monreale e la scultura romanica in Sicilia, Palerme, 1962, p. 92. 
Pantocrator à Nuestra Señora de la Asuncíon à Tuesta, et au XIII ${ }^{\mathrm{e}}$ sur l'arc d'entrée de Santibãnez del Rio en Espagne ${ }^{120}$, ainsi que sur le mur extérieur nord de l'église de Lolme en Dordogne (seconde moitié du XII ${ }^{\mathrm{e}}$ siècle). Le second vers a été, en outre, inscrit en 1271 dans l'épitaphe de Douce de Montrouche à Saint-Génis-desFontaines $^{121}$, au début du XIV ${ }^{\mathrm{e}}$ siècle à l'ancien prieuré Saint-Orens d'Auch ${ }^{122}$, en 1327 dans l'épitaphe d'Adémar de Saint-Pastor au cloître de Saint-Bertrand-de-Comminges ${ }^{123}$, au XV ${ }^{\mathrm{e}}$ siècle dans une épitaphe venant de la chapelle du château de La Bâtie-Rolland ${ }^{124}$. Dans cette dernière le premier vers :

DA TUA, DUM TUA SUNT, QUIA POST MORTEM TUA NON SUNT

se rencontre dans de nombreux manuscrits et recueils de sentences $^{125}$.

Saint Malachie, évêque d'Armagh, mort à Clairvaux en 1147, répétait sans cesse deux vers d'invitation à l'humilité :

Spernere mundum, spernere sese, spernere nullum,

Spernere se sperni, quatuor haec bona sunt.

Ces vers ont été attribués à Hildebert de Lavardin ${ }^{126}$, mais ne seraient pas de lui. Ils se trouvent dans différents manuscrits, notamment à la Bibliothèque municipale de Troyes ${ }^{127}$, et sur le tombeau d'Henri le Large à Saint-Étienne de Troyes en 1180 on pouvait lire sur les phylactères de deux anges : SPERNERE MUNDUM, et : SPERNERE SESE ${ }^{128}$.

Les rapprochements que l'on peut faire entre des inscriptions de lieux éloignés les uns des autres supposent l'intermédiaire de manuscrits qui auront voyagé entre bibliothèques, car ils sont trop nombreux pour être dus à des voyageurs qui auraient copié un texte

120. Enciclopedia del Romanico en Castilla y León. Salamanca, 2002, p. 325-353.

121. C.I.F.M., 8, p. 71.

122. Revue de Gascogne XV, 1874, p. 516, et XVII, 1876, p. 8-11 et h.-t.

123. C.I.F.M., 11, p. 144-145.

124. H. Desaye et M. Bois, « L'inscription gothique de La Bâtie-Rolland », Revue drômoise, 1992 , p. $25-27$.

125. H. Walther, Proverbia sententiaeque latinitatio Medii Aevi, II/3, Göttingen, 1963, p. 591, $\mathrm{n}^{\circ} 4861$, et II/3, 1965, p. 616, n²0051.

126. Patrologie latine, t. 171, col. 1437.

127. B. Hauréau, Notices et extraits de quelques manuscrits latins de la Bibliothèque nationale, Paris, I, 1890, p. 384, et Initia operum scriptorum latinorum..., Turnhout, VI, 1973, p. 184 ; R. Bultot, « Les meditationes pseudo-bernardines sur la connaissance de la condition humaine. Problèmes d'histoire littéraire », Sacris erudiri 15, 1964, p. 280 (Troyes, ms. 1317, fol. 175 V $^{\circ}$ ).

128. X. Dectot, « Les tombeaux des comtes de Champagne (1151-1284). Un manifeste politique », Bulletin monumental 162-1, 2004, p. 52. 
et l'auraient fait inscrire en leur lieu de résidence. En voici quelques exemples significatifs :

Le distique inscrit sur le tombeau du duc d'Aquitaine GuiGeoffroi-Guillaume à Saint-Jean-de-Montierneuf de Poitiers en 1087 :

\section{GLORIA SUBLIMIS ET SIC TUMULATUR IN IMIS DUM MORIENDO RUIT, GLORIA NULLA FUIT}

se trouve aussi dans l'épitaphe du chanoine Étienne à la cathédrale d'Agen. Peut-être en ce cas précis y a-t-il pu y avoir une transmission du fait de Simon, ancien chanoine de Saint-Hilaire-le-Grand de Poitiers, évêque d'Agen, mort en 1101.

- Il ne peut pas y avoir une explication de ce genre pour l'inscription : SIT PAX INTRANTI GRATIA SIT (ou SIT GRATIA) DIGNA PRECANTI, qui se rencontre à Villemartin de Sotoscueva en Castille en 1175, à l'entrée du Sacro Speco de Subiaco en 1190-1200, à l'entrée de Saint-Pontien de Spolète au XII ${ }^{\mathrm{e}}$ siècle, à un portail de Cingoli en 1214 et un autre portail de Cingoli de 1481 .

- Le distique

SINE MENTE BONA NEQUE VOTA VALENT NEQUE DONA ERGO MALAS MENTES DEPONANT INGREDIENTES

se lit au linteau de l'église de l'Assomption à Vieu (Ain), et à S. Adriano de Bonar en Espagne au XII ${ }^{\mathrm{e}}$ siècle.

- Cité dans différents manuscrits ${ }^{129}$ un amusant distique :

STET DOMUS HAEC DONEC FLUCTUS FORMICA MARINOS EBIBAT, ET TOTUM TESTUDO PERAMBULAT ORBEM

a été inscrit au milieu du XII ${ }^{\mathrm{e}}$ siècle en l'église de Paray-leMonial, en 1179 en l'abbaye Saint-Maurice de Clohars-Carnoët, au $\mathrm{XIII}^{\mathrm{e}}$ siècle aux Cordeliers de Toulouse, et inspire une inscription très proche d'une maison de Külsheim en Allemagne en 1614.

Lire

HIC DOMINUS MAGNUS LEO CRISTUS CERNITUR AGNUS

129. H. Walther, op. cit. (n. 125), I/1, p. 976, n 18621 ; II/5, p. 128, n 30346 ; B. Hauréau, Initia operum scriptorum latinorum, VI, p. 195. 
au tympan du grand portail de la cathédrale de Vérone et sur un chapiteau du cloître de la cathédrale de Monreale au XII ${ }^{e}$ siècle peut être la conséquence de contacts personnels, mais c'est peu probable pour le distique :

\section{VOS QUI TRANSITIS, QUI CRIMINA FLERE VELITIS \\ PER ME TRANSITE QUONIAM SUM JANUA VITE}

inscrit aussi bien dans la cathédrale d'Avellino en Italie qu'au tympan de l'église de Saint-Marcel-lès-Sauzet dans la Drôme (XII ${ }^{\mathrm{e}}$ XIII' ${ }^{\mathrm{e}}$ siècle), ou pour l'invitation :

RESPICE QUI TRANSIS, QUI CRAS INCERTUS ES AN SIS

ET QUAM SIT TIBI PRAESTO MORS EX ME MEMOR ESTO,

qui figure aussi bien dans l'épitaphe de l'évêque de Cahors Gérard à Grandmont vers 1199 que dans l'épitaphe de l'évêque Philippe de Dreux en la cathédrale de Beauvais en 1217.

De même lit-on et dans l'épitaphe de Raimond de Felgar aux Jacobins de Toulouse en 1270 et dans l'épitaphe du vicomte de Blois Renaud de L'Isle à Notre-Dame d'Évron en 1277 :

VIRGO MARIA DEI PRAESENTET HUNC FACIEI UT SIC FIAT EI DIC MISERERE MEI.

- Hans Walther a relevé dans des manuscrits des $\mathrm{XIV}^{\mathrm{e}}, \mathrm{XV}^{\mathrm{e}}$ et $\mathrm{XVI}^{\mathrm{e}}$ siècles le conseil de penser au pauvre lorsqu'on se met à table :

CUM SIS IN MENSA PRIMO DE PAUPERE PENSA ${ }^{130}$

qu'on trouve inscrit à Santa Columba de la Vega (León) en $1280^{131}$, et sur une salière en étain au Musée national du Moyen Âge à Paris vers $1330^{132}$.

-L'épitaphe inscrite sur la tombe de Rosamonde Clifford, maîtresse d'Henri II Plantagenêt à Godstowe en Angleterre :

HIC JACET IN TUMBA ROSA MUNDI NON ROSA MUNDA NON REDOLET SED OLET QUOD REDOLERE SOLET

semblerait devoir être unique avec son jeu de mot entre le nom de la défunte et l'expression ROSA MUNDI, mais le distique est repris sur

130. H. Walther, op. cit. (n. 125), I/1, p. 189, n 3784.

131. Enciclopedia del Románico en Castilla y León. p. 497 : quis in mensa, etc.

132. F. de Guilhermy, Inscriptions de la France du ve au XVIII ${ }^{e}$, tome V. Ancien diocèse de Paris, Paris, 1883, p. 150. 
la tombe de Vital de Ardengost, clerc et prêtre du chapitre au cloître de Saint-Bertrand-de-Comminges en 1334.

- Ces correspondances se trouvent encore à la fin du Moyen Âge :

HAS INTRANDO FORES VESTROS COMPONITE MORES

HINC INTRANS ORA TUA SEMPER CRIMINA PLORA

au portail de la cathédrale de Maguelone dans 1'Hérault en 1178, était aussi à la porte du grand portail de la cathédrale de Bourges vers 1388, et l'épitaphe du transi de Guillaume de Harcigny au Musée d'archéologie de Laon en 1393 :

DEO ET NATURE REDDO SIMPLICIA

ACTA COMPOSITI SINT DEO GRATA

« À Dieu et à la nature je rends mes éléments simples,

puissent les actes de leur composé être agréables à Dieu »

est aussi vers 1421 dans l'épitaphe de Robert Charmolue, clerc du diocèse de Soissons, médecin, au Musée de la ville de Poitiers ${ }^{133}$. Il est ici probable que Charmolue avait connu Harcigny, médecin comme lui et de la même région.

\section{Formulaires?}

On ne peut pas bien faire la distinction entre des formulaires qu'ont pu avoir à leur disposition les auteurs d'inscriptions, et les simples recueils d'inscriptions ou épitaphiers qui pouvaient circuler dans la même région ou au-delà. Il y a, en tout cas, des inscriptions qu'on peut penser liées par leur proximité.

Il y a eu, à l'évidence, des emprunts entre les différentes épitaphes des papes à Rome. L'exemple le plus éloquent est celui de l'épitaphe de Benoît VII à Sainte-Croix de Jérusalem en 983, dont treize des dix-sept vers sont empruntés à des épitaphes de papes de fin $\mathrm{IX}^{\mathrm{e}}-\mathrm{X}^{\mathrm{e}}$ siècle.

1. Hoc Benedicti papae quiescunt membra sepulcro

(Hoc Stephani papae clauduntur membra sacello

Étienne VI $(†$ 897)

Vatis Anastasii quiescunt membra sépulcre)

Anastase III (†913)

2. Septimus existens ordine quippe patrum

(Sextus dictus erat ordine quippe patrum Étienne VI

Tertius existens ordine pontificum) Anastase III

133. Fr. Baron, « Le médecin, le prince, les prélats et la mort : l'apparition du transi dans la sculpture française du Moyen Âge», Cahiers archéologiques 51, 2003-2004, p. 135 et 137, fig. 15. 
3. Hic primus reppulit Franconis spurca superbi (même vers, avec Formosi, pour Étienne VI)

4. Culmina qui invasit sedis apsotolicae (même vers pour Étienne VI)

5. Qui dominum quae suum captum in castro habebat

6. Carceris interea vinclis constrictus in imo

7. Strangullatus ubi exuerat hominem (les deux vers dans l'épitaphe d'Étienne VI)

8. Cumque pater multum certare dogmate sanctorum (même vers pour Étienne VI, sauf sancto en finale. On a dogmate sancto dans les épitaphes d'Hadrien $\mathrm{I}^{\mathrm{er}}$ en 795 et de Nicolas $\mathrm{I}^{\mathrm{er}}$ en 868 ).

9. Expulit a sede iniquus namque innvasor

10. Hic quoque predones sanctorum falce subegit (Hic invasores sanctorum falce subegit Serge III, † 911)

11. Romanae ecclesiae judiciisque patrum (même vers dans l'épitaphe de Serge III)

12. Hiccae monasterium statuit monachosque locavit (monachosque locavit dans l'épitaphe du métropolite Serge, $†$ 981)

13. Qui laudes Domino nocte dieque canunt

14. Confovens viduas necnon et inopesque pupillos

15. Ut natos proprios assidue refovens

16. Inspector tumuli compuncto dicito corde

17. Cum Christo regnes, O Benedicte, Deo.

(Les quatre derniers vers sont pris dans l'épitaphe de Benoît IV, $†$ 903, sauf le premier mot du $14^{\mathrm{e}}$ vers, despectas au lieu de confovens $)^{134}$.

Il y a de clairs rapports de proximité dans le HIC JACET IN / TUMBA THESAURI MAGNA COLUMNA que l'on a à Saint-André-leBas à Vienne mi-XI ${ }^{\mathrm{e}}$ siècle et à Saint-Paul de Lyon au XI ${ }^{\mathrm{e}}-\mathrm{XII}^{\mathrm{e}}$ siècle, comme dans le

HUNC INTRARE CHORUM CEPIT GREX CANONICORUM

qui est à la collégiale Notre-Dame de Lens en 1028 et à la cathédrale de Soissons en 1212,

dans le CUM PIETATE GRAVES CUM GRAVITATE PII de l'épitaphe de Burchard, évêque de Meaux († 1134) à Saint-Victor de Paris, et le CUM PIETATE GRAVIS CUM GRAVITATE PIUS de l'épitaphe de l'abbé de Saint-Denis Suger $(\dagger 1151)$ composée par Simon Chèvre d'Or, chanoine régulier de Saint-Victor.

On peut encore citer :

- TE GENUS ET PROBITAS TE LAUDET GRATIA MORUM

134. Le Liber Pontificalis, L. Duchesne (éd.), II, p. 258 ; Poetae latini aevi carolini, V, p. 336. 
à l'abbaye de Longpont (Aisne) pour le comte Raoul en 1236, et à l'abbaye de Beaupré à Achy (Somme) pour Raoul de Clermont fin XIII' $s$.

\section{- HUC CURRENTES LAUDENT PER SECLA GENTES}

à la cathédrale de Ferrare, et HUNC CONCURRENTES LAUDENT PER SECULA GENTES à la cathédrale de Vérone au XII ${ }^{\mathrm{e}}$ siècle.

- GLORIA QUID GENERIS, QUID HONOR, QUID COPIA PRODEST

IN MODICUM CINERIS LABITUR OMNE QUOD EST

dans l'épitaphe du doyen Fernando en la salle capitulaire de la cathédrale d'Oviedo en 1267, et dans l'épitaphe de Didacus en l'église de Grandas de Salime, aussi dans les Asturies, en 1297.

- VIVAT UT IN CELIS PETE SUPPLEX QUISQUE FIDELIS

à Disibodenberg en Allemagne au XII ${ }^{\mathrm{e}}$ siècle,

et

VIVAT UT IN CELIS HOC ORET QUISQUE FIDELIS

à Saint-Boniface de Freckenhorst au milieu du XIII ${ }^{\mathrm{e}}$ siècle.

«Toi qui me vois, pourquoi ne méprises-tu pas ce qui est mortel, car tout homme est enfermé dans une telle maison »

QUI TUMULUM CERNIS CUR NON MORTALIA SPERNIS

TALI NAMQUE DOMO CLAUDITUR OMNIS HOMO

Ce distique, avec parfois cum ou dum à l'incipit, figure dans de très nombreux manuscrits ${ }^{135}$. On le trouve avec tu qui me cernis à l'incipit en 1'abbaye de Silos au XII ${ }^{\mathrm{e}}$ siècle $^{136}$, mais il a une fortune particulière dans le Midi de la France et notamment en Roussillon : Rivesaltes en 1258, Villefranche-de-Conflent en 1269, Perpignan en 1270-1275, Espira-de-l'Agly et Malloles en 1280, Thuir après 1280, Elne et Villefranche-de-Conflent en 1269 et à Passa en 1304, 1311, 1323. Il faut donc que les auteurs d'épitaphes aient eu dans cette région, à partir du milieu du XII ${ }^{\mathrm{e}}$ siècle un manuscrit où ils ont pu trouver ce modèle, ou qu'il y ait eu un atelier disposant de ce distique parmi ses formules. Ce distique a d'ailleurs eu une très large

135. H. Walther, Carmina Medii Aevi posterioris latina, $\mathrm{I} / 1, \mathrm{p} .252, \mathrm{n}^{\circ} 4990$ et p. $818, \mathrm{n}^{\circ} 15715$; II $/ 1$, p. $549, n^{\circ} 455$ et p. $844, n^{\circ} 6762 ;$ II $/ 4$, p. $297, n^{\circ} 248850$. On peut y joindre le ms. 1317 de la Bibliothèque municipale de Troyes, fol. $175 \mathrm{v}^{\circ}$.

136. Dom Marius Ferotin, Histoire de l'abbaye de Silos, Paris, 1897, p. 292-293. 
fortune ${ }^{137}$ et on le rencontre à la cathédrale de Toulon en 1239 (qui tumulum cernit), à Sombreffe en Belgique en 1284 (cum tumulum cernis), à Vienne fin XII ${ }^{\mathrm{e}}$ siècle, au Musée de Rouen fin XIII ${ }^{\mathrm{e}}$ s., à la Trinité de Vendôme au XIV ${ }^{\mathrm{e}}$ siècle, à Saint-Victor de Paris en 1432, à Mayence en 1445, à Augis-sur-Aubois (Cher) en 1473. Le second vers à Monastir-del-Camp et à Passa en Roussillon :

MUNDO NE CREDAS QUIA NESCI QUANDO RECEDAS,

figure aussi dans des manuscrits ${ }^{138}$.

Pierre Alphonse, dans sa Disciplina clericalis, parle d'un philosophe qui passe dans un antique cimetière et lit :

Tu prope qui transis nec dicis aveto resiste Auribus in cordis haec mea verba tene.

Sum quod eris, quod es ipse fui, amarae mortis ${ }^{139}$.

Il est des formules heureuses, véhiculées par de nombreux manuscrits ${ }^{140}$, qui, à partir du XII ${ }^{\mathrm{e}}$ siècle se répandent dans toute la chrétienté. Ainsi de ce distique, qui reprend une partie d'un vers de Pierre Alphonse :

Quisquis ades, qui morte cades, sta, perlage, plora sum quod eris, quod es ipse fui, pro me precor ora.

Il connaît des petites variantes, respice à la place de perlege, ante au lieu de ipse, si quis remplaçant quisquis, modicum cineris au lieu de quod es ante fui, mais on le trouve partout: Arpavon (Drôme) en 1148, Las Huelgas près de Burgos en 1194, Saint-Jean-de-Latran à Rome fin XII ${ }^{\mathrm{e}}$ s., Alporão au Portugal en 1279, Béon (Yonne) au début du XIII ${ }^{\mathrm{e}}$ s., Leitzkau en Allemagne en 1279, Sainte-Ursanne en Suisse vers 1300, Amiens vers le XIII ${ }^{\mathrm{e}}$ s., Limoges, au XIII ${ }^{\mathrm{e}}$ s., Saint-Seine-l'Abbaye (Côte-d'Or) en 1350, Crespin (Nord) en 1407. Le chanoine Jean de Renard lit ce distique sur une épitaphe très ancienne de la cathédrale de Noyon et demande qu' on l'inscrive sur son tombeau en 1521. On le trouve encore à Saints-Gervais-etProtais à Gisors en 1526.

137. Espérandieu, " Note sur deux célèbres vers léonins de la période médiévale », Bulletin archéologique du Comité des travaux historiques et scientifiques, année 1888, p. 405-410.

138. H. Walter, op. cit. (n. 135), II/2, p. 1000, nº 15628.

139. Patrologie latine, t. 157, c. 705.

140. H. Walter, op. cit. (n. 135), I/1, p. 841, n 16140 ; II/4, p. 403, n 25516 ; II/5, p. 181, $\mathrm{n}^{\circ} 30636$. 
Et il faut encore penser à des florilèges ou des sylloges lorsqu'on lit le même vers en des lieux éloignés les uns des autres comme

PRAE CUNCTIS HUMILIS CUNCTIS CARUS SIBI VILIS

au XI ${ }^{\mathrm{e}}-\mathrm{XII}^{\mathrm{e}}$ siècle à Saint-Pierre-et-Saint-Paul à Avignon, en 1240 à Villiers-en-Brabant, ou :

\section{NOBILIS EX GENERE SED NOBILIOR PIETATE}

à la cathédrale de Narbonne en 1286, à Maulbronn en Allemagne en 1442 .

Les emprunts se font aussi en changeant un ou deux mots :

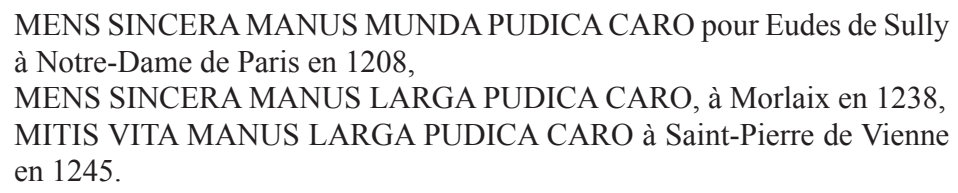
en 1245 .

On peut en rapprocher le mens pia, larga manus inscrit à la cathédrale de Troyes en 1180, à San Marco de León en 1184, à la cathédrale d'Oviedo en 1272, et le proche mens sancta, larga manus de l'abbaye de Valdedios en 1260.

Le pauper sibi dives egenis de la Trinité de Caen en 1083 est emprunté par Simon Chèvre d'Or dans une épitaphe à Pontigny en 1151 ou peu après, et peut être à rapprocher du parcus sibi dives egenis de Saint-Pierre de Vienne à la fin du $\mathrm{XI}^{\mathrm{e}}$ siècle et du parcus sibi largus egenis de Saint-Vaast d'Arras en 1228 ou du sibi parcus largus egenis des Jacobins de Chartres en 1276. Le parcus sibi largus egenis avait été inscrit à Saint-Ouen de Rouen sur le rouleau de Vital, abbé de Savigny, mort en 1122.

Sylloges, qui recueillent les inscriptions de toutes natures d'un monument, d'une ville, relevés de textes au cours d'un voyage, recueils de poèmes épigraphiques, florilèges d'inscriptions de caractères variés ou de mêmes sujets, épitaphiers sont tout autant de vecteurs de circulation de textes qui ont pu être copiés ou imités. Il $\mathrm{y}$ a eu cependant aussi, très probablement, des formulaires proprement dits. C'est le cas de fabrications en ateliers. Un bon exemple en est fourni avec les coupes de bronze romanes gravées étudiées par Josefa Weitzmann-Fiedler ${ }^{141}$. On les rencontre principalement 
en Europe centrale et septentrionale. Une trentaine de figures sont consacrées aux Vices ou aux Vertus et aux Vices. Dans presque tous les cas le vice central est la Superbia, l'orgueil, et les autres vices qui en découlent sont donnés dans le même ordre, idolatria, invidia, ira, luxuria, libido, et encore dolus, odium. La coupe du Museo civico d'Orvieto a, en outre, crapula, fraus, emulacio, ambitio, qu'on trouve aussi sur une coupe du British Museum ; sur cette dernière on a malicia, ebrietas, crapula, emulatio, contentio, ambicio, suspicio, dolus, peccatum, pigricia, vana gloria qui figurent également sur une coupe du Metropolitan Museum à New York. Dans dix coupes l'orgueil, le vice d'où dérivent tous les vices, est accompagné du même pentamètre :

\section{HAC RADICE MALA NASCITUR OMNE MALUM.}

On les trouve dans les Musées d'Arnhem aux Pays-Bas ${ }^{142}$, de Minden ${ }^{143}$ et de Nuremberg en Allemagne, de Londres, de Riga en Lettonie, de Tartu (Dorpat) en Estonie. C'est la mise en vers de l'affirmation de Grégoire le Grand dans les Moralia in Job : radix quippe cuncti mali superbia est ${ }^{144}$. On a la contrepartie de la vertu principale, l'humilitas, entourée du vers :

HAC RADICE BONA NASCITUR OMNE BONUM À HANOVRE, MÜNSTER, ZBOROWO ${ }^{145}$.

Formulaires encore dans la réalisation des cloches, dues à des fondeurs de cloches spécialisés. Les formules se retrouvent partout en Occident et elles se poursuivront longtemps, puisqu'on les emploie encore au $\mathrm{XX}^{\mathrm{e}}$ siècle, comme on peut le constater avec la thèse doctorale de Salvador A. Mollá i Alcañiz qui étudie les 2024 cloches portant des inscriptions dans la région de Valence ${ }^{146}$. Ces inscriptions peuvent indiquer simplement la fonction de la cloche,

142. J. Weitzmann-Fiedler, « Romanische gravierte Bronzeschalen Nachträge zu den 1981 erschienenen Werk », Zeitschrift des deutschen Vereins für Kunstwissenschaft XXVII, 1983, p. 8.

143. S. Wehking, Die Inschriften der Stadt Minden, Wiesbaden, 1997, p. 30, n 21 (Die Deutschen Inschriften, 46).

144. Patrologie latine, t. 76, col. 621a. Grégoire est tributaire d'Augustin (ibid., t ; 34, col. 436-437) et le point de départ de la réflexion est évidemment l'Ecclesiastique ou Siracide. Voir R. Faveau, «Initium omnis peccati superbia (Ecclesiastique, X, 15) », dans Iconographica. Mélanges offerts à Piotr Skubiszewski, Poitiers, 1999 (Civilisation médiévale, 7), p. 91-100.

145. A Münster avec l'erreur de mettre ces vers autour de la superbia, à Zborowo, avec seulement : HAC RADICE.

146. Escrituras en campanas. Incripciones en las campanas de la comunidad Valenciana datos para su estudio y corpus justificativo, Université de Valence, 1997, 2 vol. dactyl. 
qui loue Dieu, appelle le peuple, rassemble le clergé, pleure les défunts, met la peste en fuite, solemnise les fêtes :

\section{LAUDO DEUM, PLEBEM VOCO, CONGREGO CLERUM DEFUNCTOS PLORO, PESTEM FUGO, FESTA DECORO}

Ce texte figure sur une cloche de Notre-Dame-du-Bourg à Rabastens en 1280, sur des cloches de la région de Metz en 1350, de Saint-Gaudens en 1356, de Beauvais en 1387, de l'ancienne cathédrale de Genève en 1407, d'Argelès au XV siècle; dans la région de Valence on en a onze exemples de 1681 à 1992.

On attribuait aux cloches une vertu de protection contre le mauvais temps, et on sonnait les cloches pendant les orages. Ecce crucem Domini, fugite partes adverse, vicit leo de tribu Juda radix David, est une adjuracio contra grandinem, une oraison contra fulgura et tonitrua, une benedictio contra tempestates ${ }^{147}$. C'est aussi une antienne de Pâques et des fêtes de l'Invention et de l'Exaltation de la Croix ${ }^{148}$. Elle figure sur une cloche de Corneilla-de-Conflent du XIV ${ }^{\mathrm{e}}$ siècle, une cloche de Souvigny en 1403, de Llanes dans les Asturies au $\mathrm{XV}^{\mathrm{e}}$ siècle, et dans la région de Valence on a en neuf exemples du $\mathrm{XV}^{\mathrm{e}}$ siècle à 1802. À la différence de la précédente inscription le texte qui figurait sur le tombeau de sainte Agathe, protectrice de Catane contre les éruptions de l'Etna, se trouve presque exclusivement sur des cloches, sous la forme de l'accusatif qui est celle de la liturgie de la fête d'Agathe ${ }^{149}$ :

Mentem sanctam spontaneam, honorem Deo et patriae liberationem ${ }^{150}$.

Il figure sur des cloches à San Miguel de Barcena dans les Asturies en 1023, à la cathédrale d'Andria en Italie en 1111, à Sant'Agnese à Rome au XII ${ }^{\mathrm{e}}$-XIII ${ }^{\mathrm{e}}$ siècle, à Sachseln en Suisse (musée) vers 1200, à Saint-Jean-l'Évangéliste de Ravenne en 1208, à Oviedo en 1219 et à Santa Maria de Celón en 1222 dans les Asturies, à Sidiailles (Cher) en 1235, à San Juan de Cazannes en 1267, à Saint-Jean-d'Angély en 1277, à Saint-Trophime d'Arles en 1281-1286, à Sainte-MarieMajeure en 1285 et 1291 et à S. Angelo in Pescheria en 1291 à Rome,

147. A. Franz, Die kirchlichen Benediktionen im Mittelalter, Graz, 1960, II, p. 82, 87, 92, 94.

148. Corpus antiphonalium officii, R.-J. Hesbert (éd.), Cité du Vatican, III, 1968, n 2500 , p. $185 ; \mathrm{IV}, 1970, \mathrm{n}^{\circ} 6581$, p. 150.

149. Ibid., III, n 3746, p. 333.

150. R. Favreau, "Mentem sanctam spontaneam, honorem Deo et patriae liberationem. Épigraphie et mentalités », Clio et son regard. Mélanges J. Stiennon, Liège, 1982, p. 235-244 (et Études d'épigraphie médiévale, Limoges, 1995, p. 127-137). 
à Almoster au Portugal en 1292, et à des dizaines de reprises aux $\mathrm{XIV}^{\mathrm{e}}-\mathrm{XV}^{\mathrm{e}}$ siècles et jusqu'au $\mathrm{XX}^{\mathrm{e}}$ siècle, parfois alors avec des erreurs dues à une incompréhension du texte. Cette inscription est aussi une benedictio aure (air, souffle), une prière contra nebulas (nuages), une conjuratio contra tempestatem ${ }^{151}$. On peut y joindre d'autres inscriptions campanaires moins fréquemment utilisées : Defende nos in tempestate, De fulgure et tempestate libera nos, Domine, ou encore Vox Dei clamat in tempestate (Soulan, Hautes-Pyrénées, $\mathrm{XIII}{ }^{\mathrm{e}}$ siècle).

Le verset de saint Luc $(4,30)$ Jesus autem transiens per medium illorum ibat se trouve sur diverses cloches du $\mathrm{XV}^{\mathrm{e}}$ siècle dans la France du Sud : Fleurance, Lévignac, Aix, Portet-de-Luchon, Camelas, Mondragon, Gigny et à la cathédrale de Valence en 1605. Edmond le Blant a montré que cette citation était censée réduire l'ennemi à l'impuissance, protéger dans les voyages, rendre insensible à la torture ${ }^{152}$, voire, au dire d'Albert le Grand, procurer l'invisibilité. Pour rendre l'ennemi impuissant dans les combats on pouvait aussi dire Homo factus est. On peut toutefois penser que les nombreuses inscriptions campanaires DEUS HOMO FACTUS EST $^{153}$ sont plutôt issues du Credo de Nicée que de cette croyance populaire.

Le Christus vincit, Christus regnat, Christus imperat des laudes gallicanes se trouve inscrit principalement sur des cloches, à partir $\mathrm{du} \mathrm{XI}^{\mathrm{e}}$ siècle, aussi bien en France qu'en Espagne, en Italie, en Allemagne, et les exemples se comptent par dizaines. Le Christus ab omni malo nos defendat s'inspire de la litanie des saints et se trouve sur les cloches dès le XIII ${ }^{\mathrm{e}}$ siècle (Saignon dans le Vaucluse) mais surtout aux XIV $-X^{\mathrm{e}}$ siècles. Vox Domini dérive du psaume 29 (28), 3 , et sans doute aussi de la cérémonie du baptême d'une cloche, au cours de laquelle le prêtre lave la cloche puis l'essuie en disant l'antienne ${ }^{154}$ Vox Domini super aquas multas. C'est une expression notée à Saumur en 1025, à Vérone en 1081, à Limoges, TouretteLevens, Saccourvielle au XIII ${ }^{\mathrm{e}}$ siècle, à Celón dans les Asturies en

151. A. Franz, op. cit. (n. 147), II, p. $95,100,103$

152. " D'un verset de saint Luc inscrit sur quelques anciennes cloches d'église », Bulletin monumental 59, 1894, p. 244-251.

153. En France aux XIV et XVe siècles à Souvigny (03), Saint-Léger (05), Laroque-d'Olmas (09), Aix (13), Dampniac (19), Die (26), Four et Saint-Lattier (38), Camelas, Elne-la-Roca, Montbolo, Mosset, Saint-Jean de Perpignan (66), Saumanes (84), Le Dorat (87). Dans la région de Valence onze exemples de 1429 à 1945. À Babenhausen en Allemagne au XIII ${ }^{\mathrm{e}}$ siècle.

154. Corpus antiphonalium officii, R.-J. Hesbert (éd.), IV, $\mathrm{n}^{\circ} 7918$, p. 471 : octave de l’Épiphanie. 
1222, à Göhrendorf en Allemagne fin XIII ${ }^{\mathrm{e}}$ siècle. Sur la cloche de Göhrendorf on a : Vox Domini super aquas. Gloria. Christe veni cum pace $^{155}$. On est toujours un peu dans un domaine ambigu entre liturgie et croyance populaire d'une cloche calmant la tempête, faisant fuir les démons des airs, Vox Domini sonat que tempestatem fugat dit la cloche de Saccourvielle du XIII ${ }^{\mathrm{e}}$ siècle (Haute-Garonne) ${ }^{156}$. Si l'on n'a pas en France de Christe veni cum pace, les inscriptions sur les cloches de Christus rex venit cum pace se comptent par dizaines. Il peut y avoir des inscriptions campanaires plus particulièrement retenues dans certaines régions, pour autant qu' on puisse en juger à partir des études réalisées - et consultées...-, tel le o rex glorie veni cum pace, qu'on trouve certes à Marines (Val d'Oise) au XIII ${ }^{\mathrm{e}}$ siècle, mais que l'on a plutôt dans le domaine «allemand» : onze exemples en Suisse au XIII ${ }^{\mathrm{e}}$ siècle, vingt et un en Allemagne aux $\mathrm{XIV}^{\mathrm{e}}$ et $X^{\mathrm{e}}$ siècles, deux exemples à Strasbourg en 1375 et 1379.

L'utilisation de formulaires pour les cloches ressort encore de l'emploi d'une série de "formules campanaires » sur une même cloche : Christus rex venit in pace. Deus omo cactus est. In mentem sanctam spontaneam, honorem deo Deo et patriae liberacionem à Souvigny en 1408, Deus homo factus est. Christus rex venit in pace. Defende nos in tempestate à Dampniac, en 1478, Jesus autem transiens per medium illorum ibat. Vox Domini sonat. Ave Maria à Levignac en 1499, Mentem sanctam spontaneam, honorem Deo et patrie liberacionem. Te Deum laudamus. Jesus autem transiens per medium illorum ibat, à Gigny en 1500, etc.

Les écrits des liturgistes ont tôt donné une interprétation symbolique de la crosse. Isidore de Séville au VII ${ }^{\mathrm{e}}$ siècle indique que l'on remet au nouvel évêque le bâton pastoral « afin qu'il dirige (regat) ou corrige (corrigat) le peuple qui lui est soumis ou soutienne (sustineat) les faiblesses des faibles $\gg{ }^{157}$. Le concile d'Aix-la-Chapelle de 816 dit de même que le bâton pastoral soutient les faibles, corrige ceux qui s'égarent. Innocent III donne parfaitement ce sens symbolique des trois parties de la crosse : «Elle est aiguë en son extrémité inférieure, droite au milieu, recourbée en sa partie supérieure, pour désigner que l'évêque doit aiguillonner les paresseux, diriger les

155. Die Deutschen Inschriften, 64, p. 10, $\mathrm{n}^{\circ} 7$.

156. J. Leclercq-Marx, «Vox Dei clamat in tempestate. À propos de l'iconographie des Vents et d'un groupe d'inscriptions campanaires $\mathrm{IX}^{\mathrm{e}}-\mathrm{XIII}^{\mathrm{e}}$ siècles », Cahiers de civilisation médiévale 40, 1999, p. 179-187.

157. Patrologie latine, t. 83, c. 783-784, De ecclesiasticis officiis, 1. II, c. V. 
faibles, rassembler ceux qui errent », une description que reprendra textuellement Guillaume Durand dans son Rationale divinorum officiorum $^{158}$. Le rituel de l'ordination de l'évêque développe les mêmes sens : «Reçois le bâton, signe de ton gouvernement spirituel, afin que tu consolides les faibles, confirmes ceux qui titubent, corriges ceux qui s'égarent, diriges les fidèles sur la voie du salut éternel $\gg^{159}$. Lorsqu'on a confié à l'orfèvre le soin de faire la crosse du nouvel évêque, c'est naturellement vers les écrits des liturgistes qu'on s'est tourné pour y lire ce qu'ils disaient du bâton pastoral et s'inspirer des formules qu'ils proposaient d'inscrire sur la crosse. Une des plus anciennes crosses à inscription conservées est la crosse dite de saint Lizier de la seconde moitié du $\mathrm{XI}^{\mathrm{e}}$ siècle, en la salle du trésor de l'ancienne cathédrale de Saint-Lizier. On a inscrit sur la volute :

\section{CUM IRATUS FUERIS MISERICORDIE RECORDABERIS}

« Lorsque tu seras irrité, souviens-toi de la miséricorde $»^{160}$

C'est une citation du prophète Habacuc $(3,2)$, mais c'est probablement quelque écrit liturgique qui a inspiré ce choix, que reprendra Honorius dit d'Autun, qui conseille d'inscrire sur la volute de la crosse : Dum iratus fueris, misericordiae recordaberis ${ }^{161}$. Hugues de Saint-Victor propose dans le Speculum de mysteriis ecclesiae plusieurs vers pour expliquer le sens du bâton pastoral :

Curva trahit mites, pars pungit acuta rebelles ou Curva trahit quos virga regit, pars ultima pungit ou Attrahe per curvum, medio rege, punge per imum ${ }^{162}$.

La crosse dite de saint Bernward au trésor de la cathédrale d'Hildesheim (XII ${ }^{\text {e }}$ siècle, restaurée 1497$)^{163}$ porte :

COLLIGE PER SUMMUM MEDIO REGE PUNGE PER IMUM,

158. Innocent III, De sacro altaris mysterio libri sex, 1. I, c. LXII, Patrologie latine, t. 217, c. 796 ; G. Durand, Rationale divinorum officiorum, 1. III, c. XV.

159. Le pontifical romano-germanique du dixième siècle, $\mathrm{C}$. Vogel et $\mathrm{R}$. Elze (éd.), vol. 1, Cité du Vatican, 1967, p. 222. On retrouve la même oraison ou des textes comparables dans les Pontificaux manuscrits des bibliothèques publiques de France présentés et analysés par l'abbé Victor Leroquais (Paris, 1937).

160. C.I.F.M., VIII, Paris, 1982, p. 22-23.

161. Gemma animae, 1. I, c. CCXXX, Patrologie latine, t. 172, c. 611. Sicard de Crémone recommande le même texte pour une crosse, ibid., t. 213, c. 80 .

162. Patrologie latine, t. 177, c. 354.

163. V. Elbern et H. Reuther, Der Hildesheimer Domschatz, Hildesheim, 1969, p. 20-21, n 8 , pl. 46 et (pl. coul. 1) ; Chr. Wulf, Die Inschriften der Stadt Hildesheim, Wiesbaden, 2003, p. 440-442, $\mathrm{n}^{\circ}$ 218, fig. 90 (Die Deutschen Inschriften, 58). 
qui s'inspire d'un des textes d'Hugues, tout comme la crosse d'Othon Ier († 1279), lui aussi évêque d'Hildesheim, conservée au même trésor ${ }^{164}$ :

\section{ATTRAHE PER PRIMUM MEDIO REGE PUNGE PER IMUM.}

Le curva trahit quos virga regit a été gravé, à un mot près (recta au lieu de virga) sur une crosse de Saint-Sernin de Toulouse. Il est aussi recommandé par Sicard de Crémone ${ }^{165}$.

Sur la crosse d'Othon $\mathrm{I}^{\text {er }}$ d'Hildesheim on a inscrit également :

$$
\text { COLLIGE, SUSTENTA, STIMULA, LARGA, MORBIDA LENTA, }
$$

un hexamètre léonin riche que recommande Robertus Paululus en l'attribuant à Hildebert de Lavardin ${ }^{166}$. Pierre le Chantre dans son Verbum abbreviatum donne et le premier vers qui sera sur la crosse d'Othon Ir dans les mêmes termes, et ce second vers avec attrahe au lieu de collige ${ }^{167}$. Le même hexamètre collige, sustenta, etc., recommandé aussi par Innocent III et Thomas d'Aquin ${ }^{168}$, figure sur une crosse abbatiale d'Augsbourg du premier tiers du XIII ${ }^{\mathrm{e}}$ siècle $^{169}$ et sur une crosse épiscopale du début du XIII ${ }^{\mathrm{e}}$ siècle à Amiens ${ }^{170}$. Les écrits des liturgistes ne pouvaient qu'être une source privilégiée lorsqu'on avait à réaliser la crosse d'un nouvel évêque ou abbé. Mais les mêmes textes circulent dans les florilèges, ainsi du Attrahe per primum, medio rege ${ }^{171}$, du Curva trahit quos virga regit ${ }^{172}$, ou du Collige, sustenta ${ }^{173}$. Le curva trahit mites, pars pungit acuta rebelles proposé par Hugues de Saint-Victor et Sicard de Crémone se retrouve dans un florilège avec dociles au lieu de mites $^{174}$, et est sûrement à la source du PRIMA TRAHIT PLACIDOS PARS PUNGIT ACUTA REBELLES

164. Ibid., p. $303, \mathrm{n}^{\circ} 69$, fig. 33 .

165. Mitrale, 1. II, c.v., Patrologie latine, t. 213, c. 80

166. De caeremoniis, sacramentis, officiis et observationibus ecclesiasticis, publié parmi les œuvres d'Hugues de Saint-Victor, Patrologie latine, t. 177, c. 401

167. Patrologie latine, t. 205, c. 276.

168. Ibid., t. 217, c. 796. Thomas d'Aquin, In quartum librum sententiarum magistri Petri Lombardi, Distin., XXIV, quaestio III, articulus III.

169. Suevia sacra ..., Augsbourg, 1973, p. 159-160, n 141, pl. 133.

170. G. Durand, "Richard de Gerberoy évêque d'Amiens », Bibliothèque de l'École des chartes, t. XCIX, 1938, p. 272-273. Robertus Paululus, qui propose ce texte, était un prêtre attaché à l'évêque d'Amiens (fin XII ${ }^{\mathrm{e}} \mathrm{s}$.).

171. P. Lehmann, « Mittellateinische Verse in Distinctiones monasticae et morales vom Anfang des Mittelalters », Erforschung des Mittelalters, IV, Stuttgart, 1968, p. 331.

172. B. Hauréau, « Notice sur les œuvres authentiques ou supposées de Jean de Garlande », Notices et extraits des manuscrits de la Bibliothèque nationale et autres bibliothèques, t. XXVII, Seconde partie, Paris, 1875, p. 2.

173. BnF, ms. lat. 3719 , fol. $12 \mathrm{v}^{\circ}$ (fin XII ${ }^{\mathrm{e}}$ s.).

174. P. Lehmann, op. cit. (n. 171), p. 333. 
d'une crosse de Sens fin XII ${ }^{\mathrm{e}}$ siècle ${ }^{175}$. On peut même trouver ces textes dans les sermons d'Eudes de Châteauroux ${ }^{176}$. D'autres correspondances invitent à penser à des sources communes aux auteurs d'inscriptions sur les crosses, ainsi du

STERNE RESISTENTES, STANTES REGE, TOLLE JACENTES

de la crosse d'ivoire de Godehard à Hildesheim fin $\mathrm{XI}^{\mathrm{e}}$ siècle ${ }^{177}$ et de la crosse d'ivoire de saint Annon de Cologne à Saint-Servais de Siegburg, ou de la citation de saint Paul (2 Timothée 4, 2), Argue, obsecra, increpa inscrite sur une crosse épiscopale d'Otrante du $\mathrm{XI}^{\mathrm{e}}$ siècle $^{178}$ et une crosse abbatiale de Rouen du XII ${ }^{\mathrm{e}}$ siècle ${ }^{179}$.

Les formules abondent dans les épitaphes, qu'elles viennent de formulaires locaux ou d'une tradition nourrie par les épitaphes présentes dans l'édifice ou le cimetière.

Le hic jacet, qui se poursuit jusqu'à nos jours dans notre ci-gît, se trouve à Rome dès 335, à Trèves à partir du $\mathrm{V}^{\mathrm{e}}$ siècle dans les inscriptions chrétiennes (trente-six exemples) ; et pour la même époque en Viennoise du Nord on en a seulement trois exemples, aucun en Aquitaine première, deux en Espagne visigothique, mais ce sont près de trois cents exemples que l'on relève dans les concordances des inscriptions françaises des $\mathrm{IX}^{\mathrm{e}}-\mathrm{XIII}^{\mathrm{e}}$ siècles. Le hic in pace requiescit bone memorie se rencontre à des dizaines d'exemples dans les inscriptions chrétiennes, mais disparaît ensuite. Dans les inscriptions chrétiennes on trouve la formule hoc jacet in tumulo qui se poursuivra du VIII ${ }^{\mathrm{e}}$ au XIII ${ }^{\mathrm{e}}$ siècle en France, au Portugal, en Allemagne, en Suisse, en Italie. Elle forme un hémistiche, et d'autres formules métriques se répandront à partir $\mathrm{du} \mathrm{XI}^{\mathrm{e}}$ siècle, dans tout l'Occident, lorsque se développera la pratique de l'épitaphe versifiée, hac tegitur tumba, hic jacet in tumba, quem lapis iste tegit ou quem tegit iste lapis, etc. Le verbe requiescere se trouve à des centaines d'exemples dans les inscriptions chrétiennes et les concordances des inscriptions françaises des $\mathrm{VIII}^{\mathrm{e}}$-XIII ${ }^{\mathrm{e}}$ siècles en fournissent plus de trois cent cinquante occurrences. Dans ces dernières hic requiescit in

175. C.I.F.M., t. 21, Paris, 2000, p. 172.

176. L. Hervieux, Les fabulistes latins depuis le siècle d'Auguste jusqu'à la fin du Moyen Âge, Paris, IV, 1896, p. 351.

177. Chr. Wulf, Die Inschriften der Stadt Hildesheim, p. 227.

178. R. Jurlaro, « Di una iscrizione idruntina del sec. XI per un pastorale episcopale », Vetera christianorum, anno 27, 1990, fasc. 1, p. 203-206.

179. C.I.F.M., 22, Paris, 2002, p. 268. 
pace, influencé évidemment par la liturgie des défunts, se rencontre près d'une centaine de fois, tandis que le requiescat se trouve à plus de deux cents reprises, surtout à partir du XIII ${ }^{\mathrm{e}}$ siècle. Cujus anima requiescat in pace se trouve bien à Mayence et à Uzerche au XI ${ }^{\mathrm{e}}$ siècle, et dans le Sud de la France en 1189 et 1199 mais les quelque autres cent vingt exemples sont au XIII ${ }^{\mathrm{e}}$ siècle, pour plus de la moitié d'entre eux avec un amen final. Je n'ai trouvé qu'en Allemagne le développement cujus anima requiescat in sancta ou sanctissima pace. Pour indiquer le décès les inscriptions chrétiennes disent transit ou obiit. Le transit est rare au Moyen Âge, Londres 1082, Trèves 1169, Hildesheim 1190, Mayence 1302, Pérouse 1304, alors que les concordances françaises des $\mathrm{VIII}^{\mathrm{e}}-\mathrm{XIII}{ }^{\mathrm{e}}$ siècles fournissent plus de huit cents occurrences de obiit. Les demandes de prières se rencontrent aussi sous la même formulation, soit dans tout l'Occident, comme Memento mei, inspiré de la prière du bon larron (Luc, 23, 42), ou orate pro me, soit de façon plus localisée, ainsi du Deus huic pius esto ou cui Deus esto pius qu' on a au XII ${ }^{\mathrm{e}}$ et XIII ${ }^{\mathrm{e}}$ siècle dans la moitié nord de la France, et aussi vers 1266 à Carracído en Espagne, ou des nombreux exemples d'orate pro eo en France et en Espagne du XI ${ }^{\mathrm{e}}$ au XIII ${ }^{\mathrm{e}}$ siècle, à Rome en 1300, à Trèves en 1347. Le dic miserere Deus de l'épitaphe d'Hadrien à Rome en 795 est aussi à Bénévent, Hirsau (Allemagne), Split (Croatie), Saint-Riquier, Moutiers, Marseille, sans dépasser le milieu du XI $\mathrm{X}^{\mathrm{e}}$ siècle, alors que dic ou dicas, dicat Pater Noster semble cantonné dans la France du Sud, avec une grosse concentration dans les Pyrénées-Orientales, l'Hérault et l'Aude, et avec trois emplois en Espagne.

À défaut de trouver des manuels de graveurs professionnels, il existe évidemment des traditions épigraphiques, des formulaires ${ }^{180}$ propres à une région ou à une époque. Diehl donne près de cent cinquante exemples de l'emploi de bone memorie dans les inscriptions chrétiennes ; Françoise Descombes en relève près de soixantedix exemples en Viennoise du Nord, Françoise Prévost en trouve vingt-deux exemples en Aquitaine première, et Nancy Gauthier aucun exemple en Première Belgique. On en a neuf exemples en Suisse de 505 à environ 880, trois exemples en Espagne aux

180. E. Le Blant, «Sur les graveurs des inscriptions antiques », Revue de l'art chrétien III, 1859 , p. $367-379$; R. Cagnat, « Sur les manuels professionnels des graveurs d'inscriptions romaines ", Revue de philologie, 1889, p. 51-65, entre autres, pour citer deux auteurs de référence pour l'épigraphie chrétienne et l'épigraphie antique. J.-M. Lassère, dans son Manuel d'épigraphie romaine, Paris, $2^{\mathrm{e}}$ éd., 2007, 2 vol., parle à diverses reprises des formulaires dans sa magistrale synthèse. 
$\mathrm{V}^{\mathrm{e}}-\mathrm{VI}^{\mathrm{e}}$ siècles, une trentaine d'exemples en France du Sud de 814 à 1300, pour huit en France du Nord, un exemple en Belgique en 1235, un en Allemagne en 1101. Le sub hoc titulo qui se lit à Angers, Saint-Maurice d'Agaune, Lausanne, Vienne pour les inscriptions chrétiennes, est aussi à Fécamp fin $\mathrm{X}^{\mathrm{e}}$ siècle, Rouen, Saint-Evroult, Argenteuil au XI ${ }^{\mathrm{e}}$ siècle, Airvault au début du XII siècle. Peut-être le fait de trouver sub hoc conditorio dans l'épitaphe de Charlemagne à Aix explique-t-il que la formule ait été employée à Ligugé, Auxerre, Saint-Remi de Reims aux $\mathrm{IX}^{\mathrm{e}}-\mathrm{X}^{\mathrm{e}}$ siècles. Le qui legis hunc titulum d'Ausone ou Théodulphe se trouve à Cambrai au $\mathrm{IX}^{\mathrm{e}}$ siècle, Trèves et Poitiers au XI ${ }^{\mathrm{e}}$ siècle, Reims en 1151. On lit à Milan en 918 et à Vence en 1154 : discat qui nescit quod episcopus hic requiescit, et aux $\mathrm{XII}^{\mathrm{e}}$ et $\mathrm{XIII}^{\mathrm{e}}$ siècles discat qui nescit avec la finale requiescit à Saint-Amand-de-Coly, La Tour-sur-Orb, Châlons-en-Champagne, Fontaine-Chaalis, et l'on pourrait multiplier les exemples et composer un recueil de formules, sinon un manuel proprement dit à l'usage des auteurs d'inscriptions.

\section{Sources diplomatiques}

Il y a des rapports évidents avec les sources diplomatiques, pour ce qui touche les invocations, titulatures, notifications, fondations, indulgences, datations, anathèmes, ce qui laisse à penser que les auteurs des inscriptions ont pu être aussi les rédacteurs de chartes. On voit même parfois dans les inscriptions des formes paléographiques propres aux chartes. J'ai déjà abordé cette question de façon développée ${ }^{181}$, et je me bornerai donc à un seul exemple, l'expression Dei gratia ou gratia Dei, bien connue des diplomatistes puisqu'elle figure dans le premier diplôme de Charlemagne qui nous soit parvenu (13 janvier 769) $)^{182}$, et qu'elle sera employée par les souverains carolingiens puis capétiens et encore sous Napoléon III. Évêques, abbés, seigneurs l'emploient à partir de la fin du IX ${ }^{\mathrm{e}}$ siècle. On y voit à l'origine un « sentiment de piété », et on s'accorde pour

181. R. Favreau, L'épigraphie médiévale, Turnhout, 1997, p. 165-183 ; Id., « La notification d'actes publics ou privés par des inscriptions », dans Cinquante années d'études médiévales. À la confluence de nos disciplines. Colloque organisé à l'occasion du Cinquantenaire du CESCM $1^{\text {er }}-4$ septembre 2003, Turnhout, 2006, p. 637-662.

182. G. Tessier, Diplomatique royale française, Paris, 1962, p. 85 ; H. Wolfram, Intitulatio, I, Graz-Vienne-Cologne, 1967 (Mitteilungen des Instituts für österreichische Geschichtsforschung, XXI), p. 97, n. 53 et II, 1973 (Mitteilungen..., XXIV) cite deux exemples du VII ${ }^{\mathrm{e}}$ pour un roi et une reine. 
dire qu'on en vint à interpréter la formule comme une légitimation du pouvoir par la volonté de Dieu ${ }^{183}$. Le roi Charles VII ira même en 1443 jusqu'à interdire au comte d'Armagnac d'employer la formule « par la grâce de Dieu », qu'il juge bon de réserver à la titulature royale ${ }^{184}$. "Croyance en la providence " aussi pour les comtes d'Anjou ${ }^{185}$ ou pour Henri II Plantagenêt adoptant la formule en $1173^{186}$. L'épigraphie fournit de nouveaux exemples d'emploi de la formule. Dans une inscription de l'ancienne abbaye Saint-Pons de Cimiez à Nice, actuelle église de l'hôpital, est rappelée la restauration du tombeau de saint Pons par « Siacre, pécheur, appelé à l'épiscopat par la grâce de Dieu » (peccator, gracia Dei vocatus episcopus). Ce serait le premier emploi du Dei gratia pour un évêque, puisque l'inscription peut être datée sinon de 777, au moins du dernier quart du VIII ${ }^{e}$ siècle ${ }^{187}$. À une date voisine « Rachio, par la grâce de Dieu évêque de Strasbourg » (783-815) fait placer une tablette de plomb dans le sarcophage de saint Florent pour indiquer une translation ${ }^{188}$. Pour des abbés on peut citer Tresmirus gratia Dei abba sur la table d'autel de l'ancienne abbaye Saint-Jean de Mallast à Montolieu (Aude), en 948-960189, Guillaume, gratia Dei $a b a$, à Saint-Genisdes-Fontaines en 1019-1020 ${ }^{190}$, pour un comte, Heremannus Dei gratia comes à l'abbaye Saint-Vanne de Verdun au XI ${ }^{\mathrm{e}}$ siècle ${ }^{191}$, et par la suite à de nombreuses reprises pour des évêques, et même pour un prieur à Corneilla-de-Conflent ${ }^{192}$.

On aura noté que dans la première occurrence on est plutôt dans le registre de l'humilité puisque l'évêque se qualifie de " pécheur ».

183. A. Giry, Manuel de diplomatique, Paris, 1893, p. 318-319 ; O. Guyotjeannin, J. Pycke et B.-M. Tock, Diplomatique médiévale, Turnhout, 1993 (" L'atelier du médiéviste ", coll. dir. par J. Berlioz et O. Guyotjeannin, 2), p. 73 ; K.-F. Werner, « Königtum und Fürstentum in französischen 12. Jahrhundert », Vortrage und Forschungen, band XII, 1969, p. 199.

184. D. Vandrus-Reissner, "La formule "par la grâce de Dieu", dans les actes de Jacques IV d'Armagnac », Bibliothèque de l'École des Chartes, t. 151, 1993, p. 171-183.

185. O. Guillot, Le comte d'Anjou et son entourage au XI siècle, t. I, Paris, 1972, p. 355-356.

186. L. Deslisle, « Mémoire sur la chronologie des chartes d'Henri II roi d'Angleterre et comte d'Anjou », Bibliothèque de l'École des Chartes, t. 67, 1906, p. 361-401; H. Prentout, « De l'origine de la formule Dei gratia dans les chartes d'Henri II ", Mémoires de l'Académie nationale des Sciences, Arts et Belles-Lettres de Caen, 1918-1920, p. 341-396.

187. J. Guyon, «L'inscription carolingienne du tombeau de Saint-Pons à Cimiez », Mélanges de l'École française de Rome, t. LXXXV, 1973, p. 611-632 ; C.I.F.M., t. 14, 1989, p. 16-19, fig. 7-9.

188. R. Will, « Répertoire des inscriptions romanes de l'Alsace », Revue d'Alsace 98, 1959, $\mathrm{n}^{\circ} 36$, p. 69-70.

189. C.I.F.M., t. 12 , 1988, p. 34-36.

190. Ibid., t. 11, 1986, p. 138-139.

191. Dom Edmond Martène et dom Ursin Durand, Voyage littéraire de deux religieux bénédictins de la congrégation de Saint-Maur, $2^{\mathrm{C}}$ partie, Paris, 1717, p. 95.

192. C.I.F.M., t. 11, p. 51 
La seconde observation que fournit l'épigraphie c'est de chercher la source de la formule dans un texte de saint Paul :

Gratia autem Dei sum id quod sum, et gratia ejus in me vacua non fuit; sed abudantius illis omnibus laboravi; non ego autem, sed gratia Dei mecum, « Mais par la grâce de Dieu je suis ce que je suis et sa grâce envers moi n’a pas été vaine ; mais plus que tous j'ai travaillé, non pas moi, à la vérité, mais la grâce de Dieu avec moi » (1 Corinthiens 15, 10).

Ce verset est employé par la liturgie aux fêtes de saint Paul et de la Conversion de saint Paul ${ }^{193}$. Il est explicitement cité quatre fois dans les inscriptions. Dans le chœur des chanoines du Saint-Sépulcre de Jérusalem on lisait : E GRACIA DEI SUM ID QUOD SUM ET GRACIA EJUS IN ME VACUA NON FUIT ${ }^{194}$. Au portail central de la façade occidentale de Saint-Gilles-du-Gard la statue de Paul est identifiée par la banderole qu'il tient : GRATIA DEI SUM ID QUOD SUM ${ }^{195}$. À la porte nord de l'abbatiale de Déols, détruite en 1830 mais bien documentée, une statue-colonne représentait un personnage nimbé et barbu, en lequel l'abbé Dubouchat voyait vers 1825, un saint évêque, et Jean Hubert, en 1927, un personnage de l'Ancienne Loi. La reproduction d'un dessin tiré des Esquisses pittoresques de l'Indre dans l'article de 1927 est insuffisante pour lire ne serait-ce qu'un mot de la banderole, mais cette même reproduction reprise en 1985 permet de lire sans difficultés : GRACIA DEI SUM ID QUOD ${ }^{196}$. On trouve encore dans l'épitaphe de l'évêque Thietmar à la cathédrale de Merseburg au XIII ${ }^{\mathrm{e}}$ siècle : DEI GRATIA SUM QUOD SUM ${ }^{197}$. Il doit donc ici aussi s'agir de saint Paul. L'abbaye était d'ailleurs sous le patronage de Notre-Dame et des Saints-Pierre-et-Paul. La formule Dei gratia est donc à l'origine une citation biblique qui exprime l'humilité de celui qui a reçu une charge importante. Le fait que de nombreux personnages ecclésiastiques l'emploient va dans ce sens. L'emploi continu de cette même formule dans l'intitulatio du roi en fera une formule proprement diplomatique, où il est légitime de voir l'affirmation

193. Corpus antiphonalium officii, t. III, R.-J. Hesbert (éd.), Rome, 1968, n² 2968, p. 239 et t. IV, R.-J. Hesbert (éd.), Rome, 1970, nº 6790, p. 199.

194. S. de Sandoli, Corpus inscriptionum crucesignatorum Terrae Sanctae (1099-1291), Jérusalem, $1974, \mathrm{n}^{\circ} 41, \mathrm{p} .31$.

195. C.I.F.M., t. 13, 1988, p. 81-82 (1171-1181)

196. J. Hubert, «L'abbatiale Notre-Dame de Déols », Bulletin monumental 86, 1927, p. 47 ; Nouveau recueil d'archéologie et d'histoire de la fin du monde antique au Moyen Âge, GenèveParis, 1985, p. 404.

197. Die Inschriften der Stadt Merseburg, E. Schubert et P. Ramm (éd.), Berlin, 1968 (Die Deutschen Inschriften, 11), nº 14, p. 18. 
d'une origine divine du pouvoir, sans que pour autant disparaisse le sentiment originel d'humilité chrétienne.

\section{La liturgie}

De très nombreuses inscriptions ont leur source dans la liturgie, au point que la référence à la Bible, lorsqu'elle est repérée, doit aussi être examinée comme pouvant avoir été utilisée par le canal de la liturgie. Ainsi de la Salutation de l'ange Gabriel à Marie, Ave gratia plena (Luc 1,28), qui est le plus souvent donnée sous la forme liturgique Ave Maria gratia plena. En voici quelques exemples parmi bien d'autres.

L'Ordo commendationis animae est une suite de prières que l'Église faisait prononcer au chevet des agonisants depuis la seconde moitié du $\mathrm{III}^{\mathrm{e}}$ siècle. Elle fait référence uniquement à l'Ancien Testament et dérive de la liturgie juive des jours de jeûne... Libera, Domine, animam ejus, sicut liberasti Danielem de lacu leonum.

Libera, Domine, animam ejus, sicut liberasti tres pueros de camino ignis ardentis et de manu regis iniqui.

Libera, Domine, animam ejus, sicut liberasti Susanam de falso crimine ${ }^{198} \ldots$

Sur une plaque du $\mathrm{VI}^{\mathrm{e}}$ siècle à Nax en Suisse on a gravé :

+ QUI LIBERASTI DANIELEM DE LACU LEONE ${ }^{199}$.

Dans un monument chrétien de Podgorica au Montenegro, antérieur à 700 on a :

DANIEL DE LACO LEONIS

TRIS PUERI DE EGE CAMI[NO]

SUSANNA DE FALSO CRIMINE ${ }^{200}$.

À Rome, en 1068, à San Lorenzo fuori delle muro on avait inscrit :

OREMUS, DEUS, QUI DANIELEM A FERIS MORSIBUS AC A MEDIO FLAMMARUM PUEROS LIBERASTI, LIBERA, DOMINE, FAMULUM TUUM $^{201}$.

198. H. Leclercq, « Défunts », Dictionnaire d'archéologie chrétienne et de liturgie, IV-1, 1920, c. $435-436$

199. Corpus inscriptionum Medii Aevi Helvetiae, t. I, Chr. Jörg (éd.), Fribourg, 1977, n ${ }^{\circ}$ 15, p. 72 , fig. 21

200. H. Leclercq, op. cit. (n. 198), c. 436.

201. V. Forcella, Iscrizioni delle chiese e d'altri edifici di Roma del secolo XI ai giorni nostri, Rome, XII, $1878, n^{\circ} 564$, p. 509. 
L'épitaphe d'un vidame sur une plate-tombe de l'abbaye de Josaphat à Lèves (Eure-et-Loir) au XIII ${ }^{\mathrm{e}}$ siècle reprend à l'exception de per misericordiam Dei, la prière de la liturgie des funérailles : Anima ejus et animae omnium fidelium defunctorum per misericordiam Dei requiescant in pace. Amen ${ }^{202}$. Nombreux sont les exemples dès les $\mathrm{IX}^{\mathrm{e}}-\mathrm{X}^{\mathrm{e}}$ siècles, de la prière anima ejus requiescat in pace, ou cujus anima requiescat in pace, mais l'adjonction de per misericordiam Dei dans l'une ou l'autre formule ne se rencontre qu'à partir du deuxième quart du XIII ${ }^{\mathrm{e}}$ siècle.

L'antienne pour les défunts : Credo quod, Domine, non me derelinquas ne contemnabis me dum venero ad judicandum, sed miserabitur mei, Redemptor meus pius Deus ${ }^{203}$, se retrouve dans deux inscriptions carolingiennes à Saint-Ambroise et à Saint-Thècle de Milan ${ }^{204}$.

On lit dans le livre de Job 19, 23-24 : « Qui donnera que soient écrites mes paroles ! Qui donnera que sur l'airain elles soient gravées, qu'avec burin de fer et de plomb, pour toujours, sur le roc elles soient sculptées », avec à la suite (25-26) la prière :

Scio enim quod Redemptor meus vivit, et in novissimo die de terra surrecturus sum, et rursum circumdabor pelle mea, et in carne mea videbo Deum meum.

« Moi je sais que mon Rédempteur est vivant et qu'au tout dernier jour je me lèverai, et à nouveau je serai entouré de ma peau, et en ma chair je verrai mon Dieu. »

Ce texte est depuis longtemps employé dans l'office des défunts - et l'est encore -, avec de légers changements :

Credo quod Redemptor meus vivit, et in novissimo die de terra surrecturus sum, et in carne mea videbo Deum Salvatorum meum ${ }^{205}$.

Le texte biblique a été retenu pour l'épitaphe de l'abbesse Ariperga à San Felice de Pavie dans la seconde moitié du VIII ${ }^{\mathrm{e}}$ siècle, et sur le sarcophage du saint évêque Bernward dans la crypte de Saint-Michel d'Hildesheim au début du XI ${ }^{\mathrm{e}}$ siècle. Mais c'est le texte liturgique qui figure à Marchena près de Cordoue au V $\mathrm{V}^{\mathrm{e}} \mathrm{VI}^{\mathrm{e}}$ siècle, à Rimini fin VIII siècle, à SS.-Bonifacio-e-Alessio à Rome en 1005, à la cathédrale de Civita Castellana au $\mathrm{XI}^{\mathrm{e}}$ siècle, à l'abbaye d'Igny

202. J. Adémar et G. Dordor, « Les tombeaux de la collection Gaignières. Dessins d'archéologie du XVII ${ }^{\mathrm{e}}$ siècle », t. I, Gazette des Beaux-Arts, $116^{\mathrm{e}}$ année, 6ériode, t. 84, 1974, n 317, p. 64.

203. Corpus antiphonalium officii, R.-J. Hesbert (éd.), t. III, nº 1947, p. 114.

204. V. Forcella, Iscrizioni delle chiese e degli altri edifici di Milano, Milan III, 1890, p. 199-200.

205. Corpus antiphonalium officii, R.-J. Hesbert (éd.), IV, $n^{\circ} 6348$, p. 89. 
en 1138, à Saint-Victor de Paris en 1196, à Notre-Dame de Paris en 1227, à la cathédrale de Lincoln en 1279, à S. Prassede à Rome en 1287, à l'abbaye de Fontenay en 1307, à la cathédrale d'Oviedo au $\mathrm{XV}^{\mathrm{e}}$ siècle. C'est donc bien la liturgie qui a été préférée, la référence à Job étant de toute façon évidente.

Une série d'inscriptions en l'honneur de la croix ont aussi pour source la liturgie des fêtes de l'Invention et de l'Exaltation de la Sainte Croix. On est surpris lorsqu'on lit sur les bras de la croix au tympan de l'abbatiale de Conques :

[H]OC SIGNUM ERIT IN CELO CUM

«Il y aura ce signe dans le ciel lorsque $»^{206}$.

Il s'agit du verset et du premier mot du répons, cum Dominus ad judicandum venerit, "Lorsque le Seigneur viendra pour juger », de l'office des deux fêtes de la Croix ${ }^{207}$. C'était aussi une antienne chantée lorsque le pèlerin sur le départ était marqué du signe de la croix ${ }^{208}$.

Ce même texte a été inscrit au $\mathrm{XI}^{\mathrm{e}}$ siècle à Santa Maria di Castello à Corneto Tarquinia, et, avec le répons complet, à Eyne (Belgique) sur un triptyque avec relique de la croix ${ }^{209}$. Le hoc signum erit in celo était aussi gravé sur le sceau des évêques d'Acre en Terre Sainte ${ }^{210}$.

Dans l'office de Pâques et de l'Invention de la Sainte Croix on a l'antienne : Ecce crucem Domini, fugite partes adversae, vicit leo de tribu Juda ${ }^{211}$, « Voici la croix du Seigneur, fuyez parties ennemies, le lion de la tribu de Juda a vaincu ». L'antienne a été gravée sur une croix du milieu du $\mathrm{XI}^{\mathrm{e}}$ siècle à Erschwil212, sur un triptyque mosan de la Sainte Croix du XII siècle aujourd'hui à la Pierpont Morgan Library de New York, sur un triptyque mosan avec relique de la croix à Eyne au XII ${ }^{\mathrm{e}}$ siècle, au trésor de la cathédrale d'Aix-la-Chapelle vers 1165, à Notre-Dame de Tongres avant 1200. Cette antienne était dite aussi pour écarter orages et tempête ${ }^{213}$, ce qui explique

206. C.I.F.M., 9, Paris, 1984, p. 19 et 24.

207. Corpus antiphonalium officii, R.-J. Hesbert (éd.), t. IV, $\mathrm{n}^{\circ} 6845$, p. 213.

208. A. Franz, Die kirchlichen Benediktionen im Mittelalter, Graz, 1960, II, p. 283.

209. Ph. Verdier, «Les staurothèques mosanes... », Cahiers de civilisation médiévale 16, 1973, p. 100.

210. S. de Sandoli, Corpus inscriptionum crucesignatorum. Terrae Sanctae, Jérusalem, 1974, $\mathrm{n}^{\text {os }} 427$ et 428, p. 322.

211. Corpus antiphonalium officii, R.-J. Hesbert (éd.), t. IV, $\mathrm{n}^{\circ}$ 6581, p. 150. Vicit leo de tribu Juda est une citation de l'Apocalypse, 5, 5. p. 65 .

212. Corpus inscriptionium Medii Aevi Helvetiae, III, W. Kettler (éd.), Friburg, 1992, n ${ }^{\circ}$,

213. A. Franz, Die kirchlichen Benediktionen..., II, p. 80, 82, 92, 94. 
qu'elle figure sur des cloches, ainsi à Corneilla-de-Conflent, à Souvigny, ou encore à Llanes dans les Asturies. On rencontre encore ce texte dans des manuscrits ${ }^{214}$, ce qui n'a pu que renforcer sa diffusion. Le per crucis hoc signum fugiat procul omne malignum a un emploi comparable puisque c'est une antienne de la croix ${ }^{215}$. On le trouve à Saint-Savin au XII ${ }^{\mathrm{e}}$ siècle ${ }^{216}$, à Soria en $1214^{217}$, et, sous des formes approchées, sur des cloches à Peyrilles au XIII ${ }^{\mathrm{e}}$ siècle ${ }^{218}$ et à Meisenheim en $1387^{219}$.

Lorsqu'on bénissait le lieu où l'église allait être construite on chantait l'antienne Signum salutis pone Domine, in domibus istis, ut non permittas introire angelum percutientem, « Place, Seigneur, le signe du salut sur ces maisons, afin de ne pas en permettre l'entrée à l'ange qui frappe $»^{220}$. On trouve l'antienne dans un antiphonaire mozarabe de la cathédrale de León, du $\mathrm{X}^{\mathrm{e}}$ siècle, et le texte a été gravé à quatre reprises au $\mathrm{IX}^{\mathrm{e}}$ siècle à Oviedo - croix, mur, fontaine - et à San Martin de Salas dans les Asturies ${ }^{221}$. On 1'a encore gravé au $\mathrm{XVII}^{\mathrm{e}}$ siècle sur le palais de Cutre dans les Asturies ${ }^{222}$. Dans chacun de ces emplois le texte est inscrit autour de ou avec une croix flanquée de l'alpha et de l'omega.

On dit lors de la dédicace d'une église, haec est domus Domini et porta coeli $i^{22}$, inspiré de Genèse 28,17 . On trouve le texte liturgique à Saint-Pierre-de-l'Isle (Charente-Maritime), Beguey (Gironde), San Vincenzo de Galliano di Cantù (Italie), et à San Miguel de Neila, San Martin de Pieros, S. Marina de Valverde en Espagne, aux $\mathrm{XI}^{\mathrm{e}}$ et $\mathrm{XII}^{\mathrm{e}}$ siècles.

214. BnF, ms. lat. 3576 , fol. 123 ; ms. lat. 3772 , fol. $30 \mathrm{v}^{\circ}$.

215. A. Franz, op. cit. (n. 208), II, p. 105 n.; H. Walther, Carmina Medii Aevi posterioris latina, II $/ 3, \mathrm{n}^{\circ} 21192$, p. 780 . Le vers entier figure dans le Liber pontificalis Eichstetensis de Gundechar, évêque de Eichstätt de 1057 à 1075 (M.G.H., Scriptores, 7, 1846, p. 242).

216. R. Favreau, "Les inscriptions de l'église de Saint-Savin-sur-Gartempe ", Cahiers de civilisation médiévale 21, 1976, p. 30.

217. España sagrada, IX, p. 121

218. C.I.F.M., 9, p. 105 : Dum signat hoc signum fugiat procul omne malignum.

219. Die Deutschen Inschriften, $34, \mathrm{n}^{\circ} 69$, p. 59 : per soni[tum] s[---]m fugiat procul omne malignum.

220. Le pontifical romano-germanique du dixième siècle, C. Vogel et R. Elze (éd.), Cité du Vatican, 1963, p. 122 ; antienne chantée lors de la bénédiction de la première pierre, Le pontifical de Guillaume Durand, M. Andrieu (éd.), Cité du Vatican, 1940, p. 451.

221. R. Favreau, " La croix victorieuse des rois des Asturies (VIII $-\mathrm{X}^{\mathrm{e}}$ siècles), Inscriptions et communication du pouvoir ", dans L'écriture publique du pouvoir, A. Bresson, A.-M. Cocula et Chr. Pébarte (dir.), Bordeaux, 2005 (Ausonius Editions. Études 10), p. 195-207.

222. Fr. Diego Santos, Inscripciones medievales de Asturias, Oviedo, 1994, p. 103-105, 166-167, 248.

223. Corpus antiphonalium officii, $\mathrm{IV}, \mathrm{n}^{\circ} 680$, p. 201. 
Pour prendre un dernier exemple parmi bien d'autres, en l'ancienne salle capitulaire de la cathédrale du Puy, dite salle des morts, a été peinte dans la première moitié du XIII ${ }^{\mathrm{e}} \mathrm{s}$., une Crucifixion entourée de quatre prophètes, Osée, Isaïe, Jérémie et Philon d'Alexandrie ou Philon l'Ancien, qui passait pour l'auteur du livre de la Sagesse. Les textes des trois premiers sont tirés de leurs écrits, et utilisés dans la liturgie des Rameaux et du Samedi saint. Sur la banderole de Philon on lit :

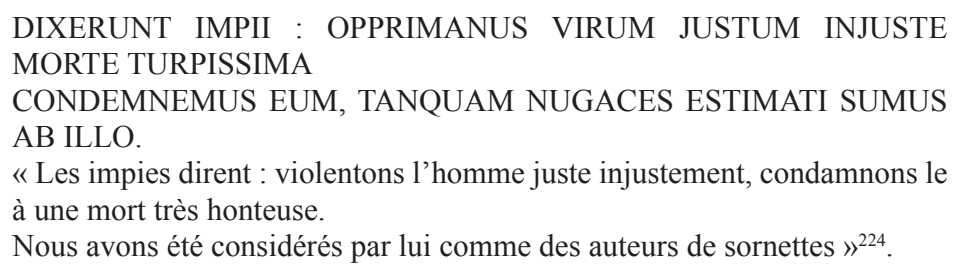

La source est ici liturgique. On lisait dixerunt impii : opprimanuus virum justum injuste le mardi saint ${ }^{225}$. Tout le texte se trouve dans la liturgie des Rameaux, du lundi et du mardi saint, dans un ordre de lecture différent ${ }^{26}$. Il comprend deux citations du livre de la Sagesse : morte turpissima condemnemus eum $(2,20)$ et tanquam nugaces estimati sumus ab illo $(2,16)$.

Les emprunts des textes des inscriptions peuvent avoir été faits à des hymnes. Si le dies irae, dies illa qu'on trouve sur un reliquaire en forme de coupole du Kunstgerwerbemuseum de Berlin et sur un reliquaire de même forme du Hessisches Landesmuseum de Darmstadt au XII ${ }^{\mathrm{e}}$ siècle ${ }^{227}$, peut être simplement une citation de Sophonie 1, 15, il est aussi tout à fait possible qu'il ait été pris à l'hymne de Thomas de Celano ${ }^{228}$, qui s'imposera dans la liturgie des funérailles. On trouve l'incipit de l'hymne d'Herimannus Contractus $(\dagger 1054)$, Salve regina ${ }^{229}$, dans des peintures murales à Goslar vers $1235^{230}$, et sur une cloche de Moissac de $1273^{231}$, et la

224. C.I.F.M., 18, Paris, 1995, p. 123-124.

225. Corpus antiphonalium officii, III, $\mathrm{n}^{\circ} 2263$, p. 155.

226. Ibid., IV, n 6464, p. 118.

227. Die Inschriften der Stadt Braunschweig bis 1528, D. Mack et A. Boockmann (éd.), Wiesbaden, 1993 (Die Deutschen Inschriften, 35), n 18, p. 25 ; Ornamenta ecclesiae. Kunst und Künstler der Romanik in Köln, 2, Cologne, 1985, p. 412-413.

228. Analecta hymnica Medii Aevi, Cl. Blumme et H.M. Bannister (éd.), t. 54, Leipzig, 1915, $\mathrm{n}^{\circ} 178$, p. 35 .

229. Analecta hymnica Medii Aevi, G. Maria Dreves (éd.), t. 50, Leipzig, 1907, p. 318.

230. Die Inschriften der Stadt Goslar, Chr. Magin (éd.), Wiesbaden, 1997 (Die Deutschen Inschriften, 45$), \mathrm{n}^{\circ} 6, \mathrm{p} .7$

231. C.I.F.M., 8, Paris, 1982, p. 183. 
strophe Tantum ergo sacramentum de l'hymne Pange lingua due à Thomas d'Aquin ${ }^{232}$, sur un huméral du musée de la collégiale de Fritzlar vers $1450^{233}$.

C'est une hymne en l'honneur de saint Christophe qui m'a permis de compléter une inscription fortement effacée d'une peinture murale à la Tour Ferrande de Pernes-les-Fontaines ${ }^{234}$ et d'une autre inscription peinte de la cathédrale du Puy, découverte en $2004^{235}$ :

\author{
CHRISTOFORI COLLO SEDEO QUI CRIMINA TOLLO \\ CHRISTOFORI SANCTI SPECIEM QUICUMQUE TUETUR \\ ILLA NAMQUE DIE NULLO LANGUORE TENETUR \\ « Je m'assieds au cou de Christophe, moi qui enlève les crimes [du monde] \\ Quiconque voit l'image de saint Christophe \\ N'est tenu ce même jour par aucune maladie. »
}

Le premier vers se trouve aussi dans une peinture murale de S. Liberatore à Castel Sant'Angelo di Visso en $1474^{236}$. Les deux vers suivants ont souvent été repris : façade de San Marco à Venise, fresque de S. Maria Assunta de Muggia Vecchia, église paroissiale de Montemaggiore, statue de la Sainte-Chapelle à Paris, peinture de l'église Saint-Serge à Angers, etc. Ce succès est dû à la piété populaire, pour laquelle voir le géant Christophe avec l'Enfant sur ses épaules était une garantie qu'on ne mourrait pas dans la journée, autrement dit qu'on serait protégée d'une mort subite sans s'être confessé et avoir reçu l'extrême-onction.

\title{
9. La Bible
}

Parmi les sources des inscriptions il y a évidement les Saintes Écritures. Presque tous les livres de la Bible sont cités dans les inscriptions. Je n'ai pas trouvé de citation pour Esther et les Maccabées, les épîtres aux Hébreux, à Tite et Philémon, mais sans doute en trouvera-t-on en élargissant le champ de recherche.

232. Analecta hymnica Medii Aevi, t. 50, n 386, p. 586

233. Die Inschriften der Stadt Fritzlar, Th. Niederquell (éd.), Munich, 1974 (Die Deutschen Inschriften, 14), n 49, p. 35.

234. R. Favreau, « L'inscription de saint Christophe à Pernes-les-Fontaines. Un apport à l'histoire du sentiment religieux », Bulletin archéologique du Comité des travaux historiques et scientifiques, n. s., 12-13, 1976-77, p. 33-39 ; C.I.F.M., t. 13, Paris, 1988, p. 178.

235. Ce sont les vers 3 et 4 de l'hymne publiée dans les Analecta hymnica Medii Aevi, t. 33, Lepizig, 1899, p. 67-68 qui sont inscrits au Puy. Ils correspondent aux vers 2 et 3 de Pernes.

236. G. Kaftal, Iconography of the Saints in Central and South Italian Painting, Florence, 1986, p. 284. 
L'épître aux Hébreux était citée en tout cas dans les inscriptions chrétiennes ${ }^{237}$.

La référence à l'Écriture peut se faire par un mot ou un nom clé. Avant d'entrer dans la terre promise Moïse envoya un homme de chacune des douze tribus d'Israël explorer la terre de Canaan. Les deux principaux de ces explorateurs seront Caleb et Josué. Les douze « parvinrent à la vallée d'Escol où ils coupèrent un sarment de vigne avec sa grappe de raisins qu'ils portèrent à deux au moyen d'une perche.... On appela ce lieu Vallée d'Escol (id est torrens botri), à cause de la grappe de raisins (botrus) qu'y avaient coupée les fils d'Israël » (Nombres 13, 24-25). Sur un couvercle d'encensoir mosan au Metropolitan Museum de New York, du milieu du $\mathrm{XII}^{\mathrm{e}}$ siècle, on peut lire :

\section{JOSUE [et] CALEP FERUNT BOTRUM.}

On a gravé sur le pied de la croix de Saint-Bertin à Saint-Omer avant 1160 :

\section{KLEF JOSUE BOTRUS.}

Sur le vitrail de la crucifixion de la cathédrale de Châlons-enChampagne (XII siècle) on lit : EX CANAAN BOTRUS, sur une croix mosane (XII ${ }^{\mathrm{e}}$ siècle) du Bristish Museum CALEB JOSUE BOTRUS, sur un reliquaire de la Vraie Croix de Notre-Dame de Tongres (XII ${ }^{\mathrm{e}}$ siècle) : BOTRUS, sur un vitrail d'Orbais (XIII ${ }^{\mathrm{e}}$ siècle) : BOTRUS. Raban Maur au IX ${ }^{\mathrm{e}}$ siècle dans son Enarratio super Deuteronomium explique que le raisin porté sur une perche est le symbole du Christ pendant sur la croix. Le premier porteur est le Juif, qui est aveugle, ne voit pas le Christ placé derrière lui et ne le reconnaît pas, le second porteur est un gentil qui, placé le dernier, voit le Christ et croit ${ }^{238}$. L'interprétation de Raban Maur sera reprise par Pierre Damien et par Rupert de Deutz ${ }^{239}$. Dans deux inscriptions du XII siècle on rappelle explicitement que la grappe portée sur une perche est la figure du Christ sur la croix :

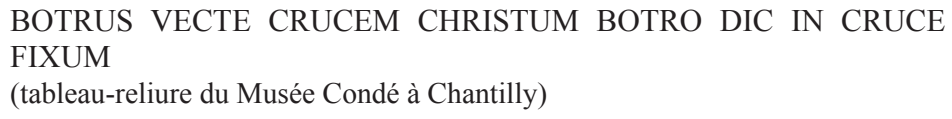

237. Ch. Pietri, «La Bible dans l'épigraphie de l'Occident latin », dans Le monde antique et la Bible, J. Fontaine et Ch. Pietri (éd.), Paris, 1985, p. 193.

238. Patrologie latine, t. 108 , c. 845.

239. Ibid., t. 144, col. 786 et t. 170 , col. 214 
QUI CRUCE PORTATUR BOTRUS BOTRO TYPICATUR

(plaque d'émail du Musée diocésain de Vienne en Autriche)

et une troisième inscription développe les figures du Juif et du Gentil :

BOTRUM RESPICERE NEGAT HIC : SITIT IPSE VIDERE

ISRAEL IGNORAT CHRISTUM, GENTILIS ADORAT

(vitrail de la cathédrale de Canterbury).

Pour le serpent d'airain que fait Moïse, sur ordre de Yahvé, serpent qui sauvera les Israélites mordus par des serpents brûlants (Nombres 21, 6-9), il n'est pas besoin de recourir aux exégètes médiévaux car le Christ lui-même a donné le serpent (d'airain) élevé dans le désert par Moïse comme le signe de sa Crucifixion : « de même que Moïse a élevé le serpent dans le désert, ainsi faut-il que le Fils de l'homme soit élevé, afin que quiconque croit ait en lui la vie éternelle » (Jean 3, 14-15). Le rapprochement est fait en deux mots sur un autel portatif des Musées royaux d'art et d'histoire de Bruxelles vers 1160 : EXALTATIO SERPENTIS, qui renvoie à Jean 3, 14 : sicut Moyses exaltavit serpentem. Sur le pied de croix de SaintBertin à Saint-Omer il a suffi de graver MOYSES SERPENS ENEI, et pour les Israélites, VULNERATI, sur une plaque semi-circulaire du Bristish Museum MOSES FILII ISRAEL, avec l'image du serpent. Sur le tableau du musée de Condé à Chantilly on a explicité : MOYSES : ASPICE SERPENTEM TIPICUM POPULOS REDIMENTEM, et l'abbé Suger a développé sur un vitrail de Saint-Denis :

SICUT SERPENTES SERPENS NECAT AENEUS OMNES CHRISTUS SIC EXALTATUS HOSTES NECAT IN CRUCE,

Et de même on peut lire sur un vitrail de la cathédrale de Cantorbéry :

MORS EST EXSANGUIS DUM CERNITUR AENEUS ANGUIS SIC DEUS IN LIGNO NOS SALVAT AB HOSTE MALIGNO.

On a même représenté sur le tympan de S. Maria zur Höhe de Soest la Crucifixion, avec un texte qui rappelle la figure du serpent d'airain, lui-même non représenté :

QUID MOYSI SERPENS NYSI TU DEUS IN CRUCE PENDENS

ILLE SALUS EREMI TU SPES ET GLORIA MUNDI.

La référence au Nouveau Testament peut aussi se faire par un mot ou un nom. « Lorsque Jésus vit Nathanaël venir vers lui, il dit : 
"Voici vraiment un Israélite, en lequel il n'est point de tromperie" " (Jean 1, 47). Dire de quelqu'un aux $\mathrm{XI}^{\mathrm{e}}-\mathrm{XIII}{ }^{\mathrm{e}}$ siècles qu'il est Israélite n'est sans doute pas ce que l'on attendrait. Mais le texte de Jean est passé dans le commun d'un martyr, d'un confesseur, d'un confesseur pontife ${ }^{240}$. On le rencontre chez Venance Fortunat ${ }^{241}$. On trouve bonus Israelita dans une inscription du Musée de Lamourguier à Narbonne fin $\mathrm{XI}^{\mathrm{e}}$ siècle, Israelita verus à Saint-Omer en 1043, moribus et vita vere ou valdus fuit Israelita à Saints-Côme-et-Damien à Rome, au Musée de Limoges au XI ${ }^{\mathrm{e}}$ siècle, à l'abbaye de Sahagun et à la cathédrale de Sens en 1202 et 1222, pius ou vir Israelita au Bec-Hellouin en 1136, vere fuit Israelita à Saint-Jacques-le-Mineur à Jérusalem au XII ${ }^{\mathrm{e}}$ siècle, à San Vicente d'Oviedo en 1232, à SaintPierre-le-Vif de Sens en 1240, et l'on a presque la citation de Jean à l'abbaye de Grandmont en 1187 : verus Israelita in quo dolus non erat. On trouve la référence à ce même verset avec seulement le mot dolus : absque dolo à Avignon en 1047, in quo dolus non fuit ullus à Eberbach en Allemagne.

Dans Luc 10, 38-42 Jésus est reçu à Béthanie par les deux sœurs Marthe et Marie. La première est préoccupée par les multiples soins du service, la seconde assise aux pieds du Seigneur, écoute sa parole. Elles représentent l'action et la contemplation, Martha labore gregi, mente Maria sibi à l'abbaye d'Arrouaise en 1097, cum Martaque pia, contemplativa Maria à Sweetheart Abbey en 1290, et on peut dire d'un ecclésiastique qu'il fut Marthe et Marie, comme un abbé à Saint-Amand-de-Coly, vers 1130, un abbé à Saint-Médard de Soissons en 1254 ou un évêque à la cathédrale de Narbonne en 1286. On peut aussi le rencontrer pour un laïc, comme à Pforzheim en 1275 .

L'emprunt biblique peut porter sur une expression. Abraham est mort à un âge avancé, in senectute bona ${ }^{242}$. L'expression se rencontre dans une série d'épitaphes, à Saint-Bénigne de Dijon aux $\mathrm{IX}^{\mathrm{e}}-\mathrm{X}^{\mathrm{e}}$ siècles, à Notre-Dame-de-Chaage à Meaux en 1158, à l'abbaye de Vicoigne en 1217, à l'ancienne cathédrale de Narbonne en 1266, à Saint-Dominique de Lisbonne en 1276, au cloître de Silos en 1280, à Saint-Dominique de Santarém en 1322. Dans l'Apocalypse, il est question à quatre reprises de la seconde mort ${ }^{243}$. Dans les épitaphes

240. Corpus antiphonalium officii, R.-J. Hesbert (éd.), III, nº 2553, p. 190, IV, n 6615, p. 158.

241. Patrologie latine, t. 88, col. 119 : quo nullos dolus est, Israelita vir es.

242. Genèse, 15,$15 ; 21,2 ; 25,8$; voir aussi Juges 8,$32 ; 1$ Chroniques 29,28 ; Tobie 14, 15.

243. Apocalypse 2,$11 ; 20,6$ et $14 ; 21,8$. 
on demande au Seigneur d'éviter au défunt une mors secunda : Trèves au VIII ${ }^{\mathrm{e}}$ siècle, Palencia au XII ${ }^{\mathrm{e}}$ siècle, Arras en 1250, Arouca (Portugal) en 1256. À la cathédrale de Jaca au XII ${ }^{\text {e }}$ siècle on a : Cor viciis munda, pereas ne morte secunda, auquel répond à Sens au XIII ${ }^{\mathrm{e}}$ siècle : hunc Deus emunda, pereat ne morte secunda. On voit combien il est difficile aujourd'hui où le texte latin de la Bible ne nous est plus familier comme il l'était pour les clercs au Moyen Âge, de repérer tous les emprunts à la Bible.

On a cité des textes de presque tous les livres de la Bible et très souvent on n'a qu'une ou deux références à des emplois dans des inscriptions. Les citations peuvent être très curieuses. Ainsi sur l'autel portatif dit d'Eilbert de Cologne au Kunstgewerbemuseum, des citations de Joël et d'Abdias. Du premier on a gravé le verset 17 du premier chapitre : COMPUTRUERUNT JUMENTA IN STERCORE SUO, «Les bêtes de somme ont pourri sur leur fumier ». Le contexte est de désolation : bêtes mortes, granges dévastées, greniers en ruine car le blé fait défaut. Saint Jérôme écrit que pourrit sur son fumier celui dont le dieu est son ventre; pour lui sont démolies les granges de la félicité future, les greniers de l'abondance éternelle et les pressoirs sont renversés, car si froment et vin manquent, c'est en vain que granges et pressoirs sont préparés. On peut retrouver là un rattachement à l'autel de la célébration eucharistique. Pour Rupert de Deutz, les bêtes qui pourrissent sur leur fumier sont ceux qui finissent leur vie dans la luxure, il faut donc confesser à Dieu ses péchés. Le verset 20 d'Abdias dit : «Les exilés de Jérusalem qui sont dans le Bosphore possèderont les cités du Midi. » Pour saint Jérôme l'exil a lieu à Sepharad, qu'il traduit par Bosphore, les cités du Midi sont dans la tribu de Juda, les fils d'Israël doivent abandonner la lettre qui tue pour l'esprit qui vivifie, la superbe des Juifs pour l'humilité chrétienne. Pour Rupert de Deutz le Bosphore est une région de la mer septentrionale, et les nations païennes qui étaient sans connaissance de Dieu dans l'obscurité et le froid possèderont les cités du Midi, c'est-à-dire la plénitude de la vraie lumière et de la chaleur, car Dieu, par sa seule grâce, a visité les nations ${ }^{244}$. On voit bien que ces textes étaient destinés au seul ecclésiastique de haut rang qui utiliserait l'autel portatif, mais ils ne s'expliquent que par le filtre des commentaires exégétiques.

244. R. Favreau, «Les autels portatifs et leurs inscriptions », Cahiers de civilisation médiévale, $46^{\circledR}$ année, 2003, p. 339-340. 
Il est aussi des citations très souvent utilisées, dans toute la chrétienté. C'est le cas de trois textes d'Isaïe et d'Ezéchiel qui annoncent la maternité de Marie, et donc l'Incarnation, et que la liturgie a retenus pour l'Avent:

Ecce Virgo concipiet et pariet filium et vocabitur nomen ejus Emmanuel (Isaïe 7, 14). On trouve ecce virgo concipiet sur un ivoire d'environ 800 à Oxford, mais toutes les autres citations sont du XII et, dans une proportion beaucoup plus faible, du XIII ${ }^{\mathrm{e}} \mathrm{s}$. (France, Italie, Allemagne, Espagne, et naturellement basilique de la Nativité à Bethélem). On observera qu'il est toujours cité sous sa forme vétéro-testamentaire et liturgique, jamais d'après la citation qu'en fait Matthieu 1, 23, qui cependant a dû influencer l'inscription peinte à San Silvestro de Tivoli : ecce virgo in utero concipiet, Matthieu disant in utero habebit et non concipiet ${ }^{245}$.

Egredietur virga de radice Jesse (Isaïe, 11, 1). La liturgie l'emploie pour l'Avent et l'Annonciation. Le texte est gravé sur un ivoire de Bamberg du début du $\mathrm{XI}^{\mathrm{e}}$ siècle, puis est inscrit dans la frise de Notre-Dame-la-Grande de Poitiers, sur un chapiteau de Conques, au portail sud de Notre-Dame-du-Port à Clermont-Ferrand, à la cathédrale de Monreale, dans les peintures de la chapelle du Liget au XII ${ }^{\mathrm{e}}$ siècle, à la voûte de Saint-Michel et sur les fonts baptismaux de la cathédrale d'Hildesheim au XIII ${ }^{\mathrm{e}}$ siècle.

Porta haec clausa erit, non aperietur, et vir non transibit per eam (Ezéchiel 44, 2). Ce n'est pas la forme liturgique employée dans l'octave de la Nativité, porta quam videtis clausam, qui sera retenue, dans les inscriptions mais le texte même d'Ezéchiel. C'est Rupert de Deutz qui appliquera ce verset à Marie, "Vierge avant l'enfantement, vierge après l'enfantement $»^{246}$. Ce texte a été inscrit sur la Vierge dite de dom Rupert au musée Curtius de Liège, dans les peintures murales de la chapelle du Liget, sur la pala d'or de San Marco à Venise, sur un vitrail des Dominicains de Wimpfen, sur des stalles des cathédrales d'Hildesheim et d'Oviedo.

Pour le Christ deux versets ont eu une particulière faveur, en dehors de l'incontournable alpha et omega (Apocalypse 1, $8 ; 21$, $6 ; 22,13)$, le verset 13 du psaume 91 (90), super aspidem et basiliscum ambulabis et le verset 5 du chapitre 5 de l'Apocalypse, Vicit leo de tribu Juda. Le psaume 91 (90) est dit presque entièrement au

245. H. Lanz, Die romanischen Wandermalerein von S. Silvestro in Tivoli : eine römisches Apsisprogramm der Zeit Innozenz III, Berne/New York, 1983, p. 83.

246. Patrologie latine, t. 167, c. 1493-1494. 
trait du premier dimanche de Carême, mais c'est plutôt le succès de l'iconographie qui l'illustre qui a entraîné cette faveur. Le vicit leo est employé dans la liturgie à Pâques et aux fêtes de la Sainte Croix. Il illustre le Christ, leo, vainqueur de la mort par sa résurrection, et a été employé dans les inscriptions chrétiennes à Rome et à Carthagène, avant d'être inscrit du $\mathrm{X}^{\mathrm{e}}$ au XII ${ }^{\mathrm{e}}$ siècle, à Fécamp, SaintRomain-le-Puy, Erschwill, New York (triptyque mosan), Moradillo de Sedano.

Le Sermon contre les Juifs de l'évêque de Carthage Quodvultdeus dans la première moitié du $\mathrm{V}^{\mathrm{e}}$ siècle ${ }^{247}$ a donné naissance à un jeu liturgique le Drame des prophètes, qui a eu un grand succès. Si quelques citations sont celles-là même de la Vulgate, d'autres sont différentes puisque Quodvultdeus, contemporain de Jérôme, avait un texte biblique employé de son temps. On y trouvera donc des citations « bibliques » particulières, qui trahissent immédiatement leur origine dans le sermon de Quodvultdeus. C'est le cas pour Deutéronome 18, 15, Isaïe, 7, 14 (Virgo in utero concipiet, cité plus haut), Baruch 36, 38, Daniel, 9, 24, Habacuc, 3, $2^{248}$.

Il faut penser à un même atelier ou à quelque autre influence lorsqu'on retrouve le même verset 8 du chapitre 13 de l'Apocaylpse, agnus qui occisus est ab origine mundi, sur deux croix du début du $\mathrm{XII}^{\mathrm{e}}$ siècle, attribuées à Roger de Helmarshausen au Kunstgewerbemuseum de Francfort et au Schnütgen Museum de Cologne et sur une troisième croix de la fin du siècle au trésor de l'abbaye de Fritzlar. Et on pourrait multiplier les exemples d'emprunts à la Bible, tant c'est, pour les inscriptions, une source essentielle.

Ce parcours des sources des inscriptions médiévales appelle bien d'autres recherches, sur les sylloges, les florilèges, les épitaphiers, des études d'évolution chronologique et de localisation des formules, etc. Et naturellement un état des citations, expressions, formules épigraphiques est nécessairement subjectif, et tout aussi naturellement à compléter et enrichir sans cesse. En commençant une lettre à Garin, abbé de Saint-Jean d'Aulps ${ }^{249}$ de 1113 à 1136, saint Bernard cite le livre de l'Ecclésiastique ou Siracide 18, 7 : "Quand un homme en a fini c'est alors qu'il commence », et il le

247. Ibid., t. 42, c. 1123-1126 ; Euvres de Quodvultdeus, R. Braun (éd.), Turnhout, 1976 (Corpus christianorum. Series latina, 60), p. 225-258.

248. R. Favreau, Épigraphie médiévale, p. 225-230, et « Controverses judéo-chrétiennes et iconographie. L'apport des inscriptions ", Comptes rendus des séances de l'Académie des Inscriptions et Belles-Lettres année 2001, p. 1267-1303.

249. Patrologie latine, t. 182, col. 459 ; Gallia christiana, XV, 1865, col. 489-490. 
félicite de garder un esprit neuf et combatif alors qu'il mériterait le repos du vieillard et la couronne d'une vie méritante. Sans chercher la moindre couronne c'est une bonne invite au chercheur de ne jamais se satisfaire du travail accompli. Il reste beaucoup à faire.

\author{
$*$ \\ $* \quad *$ \\ MM. André Vauchez, Philippe Contamine, Bernard Guenée, \\ Albert RigAUdièRE et Jean-Bernard de Vaivre, correspondant de \\ l'Académie, interviennent après cette communication.
}

\title{
LIVRES OFFERTS
}

M. Robert TURCAN a la parole pour un hommage :

« J'ai l'honneur de déposer sur le bureau de l'Académie de la part des éditeurs Vassiliki Gaggadis Robin, Antoine Hermary, Michel Reddé et Claude Sintes les Actes du $\mathrm{X}^{\mathrm{e}}$ Colloque International sur l'art provincial romain (Arles et Aix-en-Provence, 21-23 mai 2007) intitulés Les ateliers de sculpture régionaux : techniques, styles et iconographie, Centre Camille Jullian, Aix-Arles, 2009, $840 \mathrm{p}$. in- $4^{\circ}$, plusieurs centaines de figures dans le texte (cartes, dessins, photos).

Ce qu'on appelle "l'art provincial romain" est multiple et divers, comme on sait. Il faudrait plutôt parler d'arts locaux ou régionaux, si différents de style, de facture ou d'inspiration, qui portent l'empreinte des matrices classiques, mais transcrivent aussi l'expression de croyances et de sentiments propres aux milieux indigènes, urbains ou militaires. Le matériel est foisonnant, sinon déconcertant à l'occasion et bien difficile à classer, à caractériser, voire à interpréter ou même à dater. C'est un dossier sur lequel nos collègues étrangers ont travaillé davantage, notamment en Allemagne, en Suisse, en Italie où existent des enseignements d'art romain des provinces. Ce volume consigne les travaux d'un $\mathrm{X}^{\mathrm{e}}$ colloque bisannuel qui, avec une centaine d'interventions démontre le succès des recherches en la matière. La publication intégrale des actes n'allait donc pas sans difficulté. Aussi le gros mémoire de Peter Noelke paraîtra-t-il à part dans les Bonner Jahrbücher.

Manfred Hainzmann regrette avec raison dans sa conférence liminaire que l'iconographie ignore trop souvent l'épigraphie et qu'on n'ait pas fixé une typologie des stèles funéraires, dont la chronologie reste 